\title{
Use of SeaWiFS data for light availability and parameter estimation of a phytoplankton production model of the Bay of Biscay
}

\author{
Martin Huret ${ }^{a}$, Francis Gohin ${ }^{a,{ }^{*}}$, Daniel Delmas ${ }^{b}$, \\ Michel Lunven ${ }^{\mathrm{a}}$, Véronique Garçon ${ }^{\mathrm{c}}$ \\ a IFREMER Centre de Brest, BP 70, 29280 Plouzané France \\ b CREMA L'Houmeau (CNRS/IFREMER), Case 5, 17137 L'Houmeau, France \\ ${ }^{c}$ LEGOS/CNRS, 18, Avenue Edouard Belin 31401 Toulouse Cedex 9, France \\ *: Corresponding author : Francis.Gohin@ifremer.fr
}

\begin{abstract}
:
Processing SeaWiFS (Sea-viewing Wide Field-of-view Sensor) data provides useful information for the observation and modelling of the phytoplankton production of the Bay of Biscay. Empirical algorithms allow the retrieval of chlorophyll $a$ and non-living Suspended Particulate Matter (SPM) concentrations. These data are used to constrain a coupled 3D physical-biogeochemical model of the Bay of Biscay continental shelf. Two issues are investigated, depending on the variable used, to constrain the winter to spring phytoplankton production for the year 2001. First, SPM data is used as forcing data to correct the corresponding state variable of our model. This allows the realistic simulation of the light limited bloom at the end of February 2001, as observed with SeaWiFS chlorophyll a images and from the NUTRIGAS field cruise. Second, chlorophyll a data is used for parameter estimation of the biogeochemical model. The ability of assimilating these data is tested to improve the simulation of strong blooms observed in late May 2001 in the Loire and Gironde plumes. A global optimization method (Evolutive Strategies) is adapted to the complete 3-D coupled model, in order to find the best set of parameters. The hydrological conditions during the bloom can be validated with data from the PEL01 field cruise. After selection of the most sensitive parameters, the method is tested with twin experiments. Then, the use of real SeaWiFS data reduces the model/data misfit by a factor of two, improving the simulation of bloom intensities and extensions. The sets of parameters retrieved in each plume are discussed.
\end{abstract}

Keywords: Physical-biogeochemical modelling; Suspended Particulate Matter; Chlorophyll; Parameter estimation; SeaWiFS; Bay of Biscay 


\section{Introduction}

The Sea-viewing Wide Field-of-view Sensor (SeaWiFS) data, since the launch of the sensor aboard SeaStar in September 1997, has been processed with empirical algorithms adapted to the Bay of Biscay. Chlorophyll $a$ (Gohin et al., 2002) and non-living Suspended Particulate Matter (the particulate matter non-correlated to phytoplankton, hereafter referred as SPM) are thus retrieved with an acceptable reliability level (Gohin et al., 2005). This satellite database, together with the in situ observations collected during the numerous oceanic cruises carried out in the Bay of Biscay, have allowed a deeper understanding of the spatio-temporal distribution of phytoplankton. Hydrological features related to river plumes, and light availability, seem to be the two major factors regulating the winter to spring phytoplankton production in the Bay of Biscay (Morin et al., 1991; Labry et al., 2001; Gohin et al., 2003).

This ecological a priori knowledge introduced in a modelling approach can help us extrapolating in space and time the view we have of the ecosystem. In this work, we use the MARS3D hydrodynamical model of IFREMER (Lazure and Jegou, 1998; Lazure and Dumas, 2004) applied to the Bay of Biscay. With the appropriate high resolution atmospheric forcings, the main hydrological characteristics can be reproduced at the shelf scale. This model is coupled to a phytoplankton production model derived from that developed in Loyer (2001).

A critical issue of phytoplankton modelling in coastal areas is the retrieving of the amount of light in the water column, a major controlling factor of the winter primary production. For the Bay of Biscay, the model should simulate the recurrent blooms in the Loire and Gironde plumes at the end of winter. These blooms develop during sunny periods in the distal part of the plumes, where SPM concentration is low, and halostratification induces a thin mixed-layer (Labry et al., 2001; Gohin et al., 2003). The scattering and absorption of the solar irradiance depend on particulate organic and mineral matter, as well as yellow substances, the Coloured Dissolved Organic Matter (CDOM). Living organic matter and associated detritus can be deduced from the corresponding state variables of the model. Mineral suspended matter can be another state variable of the model. However, the complexity of the deposition and erosion processes and their forcings, and the variability in the quality of the constitutive particles of the sediment, are both strong sources of error in the simulation of this variable concentration.

Another complicated task is the choice of appropriate parameter values. Parameterizations often integrate several processes, for model components encompassing several families and species. In this case, associated parameters

$\overline{\text { E-mail }}$ address: martin.huret@ifremer.fr (M. Huret) 
can be highly variable. In addition, many of them cannot be directly issued from measurements, like mortality rates. Uncertainties in the parameter values are thus a major source of error in an ecosystem model. Multiplying the number of state variables becomes critical for the model stability and efficiency, mainly because it multiplies dramatically the number of degrees of freedom (Denman, 2003; Arhonditsis and Brett, 2004). Thus, the biogeochemical model we use remains quite simple, with the choice of variables depending on data available over the Bay of Biscay shelf.

Data assimilation is a promising strategy for constraining models with observations. Numerous assimilation studies show the usefulness of the highly informative chlorophyll $a$ satellite data. Most of these works have been done for estimating the parameter values of biological models (Fasham et al., 1995; Prunet et al., 1996; Gunson et al., 1999; Lellouche et al., 2000; Friedrichs, 2002; Garcia-Gorriz et al., 2003; Hemmings et al., 2003; Losa et al., 2004), rather than looking for a forecasting assimilation scheme updating the model state (Ishizaka, 1990; Carmillet et al., 2001; Natvik and Evensen, 2003), for which a much clearer understanding of the intricacies of marine ecosystems is required (Hofmann and Friedrichs, 2001). This statement is even more true for coastal areas, where physical mechanisms, biogeochemical processes, and their coupling are more sensitive and complex as compared with the open ocean.

The goal of this work is to investigate the potential improvement of our biogeochemical model by using SeaWiFS derived quantities. This goal can be articulated along two objectives. The first objective is to better constrain the light attenuation coefficient, which is a prerequisite for a good estimation of the winter phytoplankton production in coastal areas. For this purpose, we will use SPM derived from SeaWiFS images. The second objective is to derive a set of biological parameters consistent with the SeaWiFS chlorophyll $a$ observations over the Bay of Biscay. To achieve properly this calibration step, we will use an objective cost function between model and data together with a minimization routine. Several methods have been employed in the last few years, most of them based on the adjoint model (Lawson et al., 1995; Spitz et al., 1998, 2001; Gunson et al., 1999; Lellouche et al., 2000; Fennel et al., 2001; Friedrichs, 2001, 2002; Schartau et al., 2001; Garcia-Gorriz et al., 2003; Faugeras et al., 2003; Kuroda and Kishi, 2004). Other authors have used global optimization methods, like simulated annealing (Matear, 1995; Hurtt and Armstrong, 1996; Vallino, 2000) or the genetic algorithms (Athias et al., 2000; Schartau and Oschlies, 2003). The latter show best results in computational time and maximum recovery efficiency. We will use here the Evolution Strategies (Schwefel, 1995), based on the same principles than genetic algorithms, but more appropriate for continuous problems (Bäck, 1996). The method is adapted to our three dimensional coupled model. It is tested in the recovery of a parameter set allowing the correct simulation of strong blooms observed on SeaWiFS chlorophyll $a$ images in the river plumes of the 
Bay of Biscay in May 2001.

\section{The coupled model and data}

\subsection{The hydrodynamical model}

We use the MARS3D circulation model designed for shelf to small embayment scale hydrodynamics. Its principles are fully described in Lazure and Dumas (2004), with an application and discussion on the Bay of Biscay. For this reason, we present in this section only the characteristics specific to our study. MARS3D has already been used in coupled configurations with biogeochemical models in the Bay of Biscay (Loyer et al., 2001), or over the Río de la Plata estuary and shelf (Huret et al., 2005) offshore the Southeastern coast of South America.

The simulated domain extends from the coast to approximately the $200 \mathrm{~m}$ isobath at its western boundary, except in the south where the bathymetry can reach $2500 \mathrm{~m}$, and from the Spanish coast to the English Channel entrance at $49.5^{\circ} \mathrm{N}$ (Fig.1). The bathymetry is provided by the SHOM (Service Hydrographique et Océanographique de la Marine). The adaptive time step is around $1000 \mathrm{~s}$. The model is in spherical coordinates, giving an approximate horizontal resolution of $5 \mathrm{~km}$ at mid-latitudes. There are 11 sigma levels on the vertical, with thinner thicknesses for bottom and surface than for mid-layers.

The open boundary surface elevation conditions are produced by a larger barotropic $2 \mathrm{D}$ model extending from $40^{\circ} \mathrm{N}$ to $65^{\circ} \mathrm{N}$ and from $20^{\circ} \mathrm{W}$ to $15^{\circ} \mathrm{E}$. It is forced by the 8 principal tidal components from the FES99 model (Finite Element Solution) (Lefèvre et al., 2002) at its boundaries and by wind at the air-sea interface. The extended 2D model is independently run to provide the nested 3D model with consistent boundary conditions. At the open boundaries, temperature and salinity are relaxed to the climatologies of Reynaud et al. (1998) (SISMER, www.ifremer.fr) with a time lag of 13 days.

Freshwater inputs to the Bay of Biscay are supplied by the major French Atlantic rivers, among them Loire and Gironde, but also small rivers of southern Brittany. The daily discharge data as well as the monthly river temperatures were provided by the Loire-Brittany and Adour-Garonne River Basin Agencies. Wind and atmospheric pressure are derived from the Aladin model of Météo-France with a $10 \mathrm{~km}$ and 3 hours space-time resolution. Air temperature and specific humidity are derived from the coarser global model ARPEGE of Météo-France, and are used together with solar fluxes to calculate heat fluxes at sea surface. Sea surface solar irradiance is calculated from METEOSAT-7 
hourly data (Brisson et al., 1994, 2001).

\subsection{The biogeochemical and SPM models}

The biogeochemical model we used is a simplified version of the model developed in Loyer (2001) over the Bay of Biscay. The conceptual model is given in Fig.2. Phytoplankton is divided into the diatoms and dinoflagellates groups, with concentrations expressed in nitrogen currency. There is one herbivorous zooplankton component expressed in mass of carbon. Three limiting elements are considered : nitrogen, with nitrate and ammonium as inorganic nutrients, phosphorus, and silicon. Nutrients are supplied by rivers through dissolved mineral as well as particulate organic forms. These data are provided monthly or bi-monthly by French Water Agencies. The detritic organic matter is either mineralized in the water column or in the sediment (see below for sediment constitution) with specific rates. The model equations are listed in Appendix A, with detailed formulations in Appendix B. Most of the parameters are derived from preliminary modelling works on the Bay of Biscay (Loyer, 2001) and on the Bay of Seine (Cugier et al., 2004) (see Tables 1, 2 and 3).

SPM is highly variable in shelf sea regions, where tidal and wave mixing is responsible for resuspension, especially during winter months. River runoff and coastal erosion also carry highly variable concentrations of SPM into the shelf seas. The mean SPM concentrations over the bay of Biscay from a JanuaryFebruary SeaWiFS composite of the years 1998-2003 are given on Fig.3. This map reveals a strong correlation of the winter surface concentration with the bathymetry, with values up to $15-20$ g.m ${ }^{-3}$ in shallow coastal areas. To allow the representation of this SPM distribution, a non-organic SPM variable has been introduced, following Cugier and Le Hir (2000), with associated sinking rate, and deposition and erosion processes depending on the bottom shear stress. The SPM deposition allows sediment layers constitution and burial of organic matter. However modelling the winter surface concentrations as those observed on Fig.3 reveals strong uncertainties. This arises from a lack of details on quality (size, density, cohesion) of the SPM, a lack of detailed field observations to derive accurate parameterizations of processes such as flocculation, deposition and resuspension, and from the fact that we do not consider here the wave effect on resuspension. We therefore chose to use SeaWiFS SPM as a surface constraining data set to correct the model SPM state variable. The calculation of light availability for photosynthesis, taking into account the SPM modelling and correction by SeaWiFS is detailed in Appendix C. The sea surface solar irradiance is the same METEOSAT hourly data as used for heat flux calculations.

The coupled model is run for three years before the beginning of the year 2001, 
giving realistic salinity, temperature and nutrient initialization fields.

\section{3 'Ocean color' data}

Use of satellite 'ocean color' data is not a trivial issue in the coastal waters of the Bay of Biscay. These waters can be designated as Case 2, as their optical properties are substantially affected by suspended particulate inorganic matter and CDOM originating from sources other than phytoplankton. In these waters, the error in chlorophyll $a$ concentration retrieval is dramatically increased (Carder et al., 1991) when using standard algorithms like Ocean Chlorophyll 4 channels (OC4) (O'Reilly et al., 1998). An empirical approach has been proposed by Gohin et al. (2002) to retrieve chlorophyll $a$ in the coastal waters of the Bay of Biscay. First, level 1A images at $1.1 \mathrm{~km}$ resolution provided by NASA are processed with SeaDAS 4.0 to derive normalized water leaving radiances $\left(L_{n w}\right)$. Then a "look-up" table is applied to relate SeaWiFS triplets [OC4 maximum band ratio, $L_{n w}(412)$ and $L_{n w}(555)$ ] to chlorophyll $a$ concentration.

The SPM concentration can be derived from the SeaWiFS reflectance at 555 $\mathrm{nm}$, as proposed for the Bay of Biscay by Froidefond et al. (2002). Considering that phytoplankton, which quantity is related to chlorophyll, is a component of SPM, the relationship proposed by Froidefond et al. (2002) has been modified taking into account the chlorophyll $a$ derived from the "look-up" table. This method described by Gohin et al. (2005) discriminates the non-living part of SPM from the total SPM.

\subsection{In situ data}

The field cruises NUTRIGAS and PEL01 were carried out on the RV THALASSA in the northern Bay of Biscay at the end of February (February, 23 ${ }^{\text {rd }}$ to March, $1^{\text {st }}$ 2001) for the first one, and on the entire shelf during spring 2001 (April 30 $30^{\text {th }}$ - June $4^{\text {th }}$ 2001) for the second one. At each station, vertical profiles of temperature, salinity, pressure and fluorescence were measured with a SeaBird CTD (Sea-Bird Electronics, Washington, USA). Discrete water samples were collected using Niskin bottles attached to the CTD-rosette system. Samples for total chlorophyll $a$ were collected by filtration of seawater on Whatmann GF/F filters ; for size fractionation $3 \mu \mathrm{m}$ Nucleopore polycarbonate filters and $20 \mu \mathrm{m}$ nylon sieves were used. Filters were stored frozen and analysed latter by the fluorometric acidification procedure in $90 \%$ acetone extracts (Holm-Hansen et al., 1965). During the NUTRIGAS cruise a CILAS (Marcoussis, FRANCE) Particle Size Analyser (PSA) (Gentien et al., 1995) was integrated to the pelagic profiler, from which total SPM is obtained 
(Lunven and Gentien, 2000). Phytoplankton samples for species counting were preserved in a lugol-glutaraldehyde solution (1\%). Abundance of phytoplankton was determined by settling 10 or $50 \mathrm{ml}$ of water from each sample for $48 \mathrm{~h}$ in sedimentation chambers.

\section{Parameter optimization method}

\subsection{The optimization strategy}

Major attempts for optimization of ecosystem model parameters were done into local (0-D or 1-D) models, ignoring horizontal advective transport. Gunson et al. (1999) used a 1-D model following lagrangian floats and considering the water column as a closed system. Only few attempts have been made in a full 3-D model (Garcia-Gorriz et al., 2003). Considering that, in coastal regions, circulation is fully three dimensional, and that shear between water layers cannot be ignored, our parameter optimization is applied to the three dimensional coupled model. Reduced time and space domain made possible the use of a global optimization method, the Evolution Strategies (ES), which if used over the whole Bay of Biscay would have cost much computing time. As we do not consider feedback of biology on the hydrodynamics, the biological model can be run off-line during the optimization, which again reduces the computing time. We chose to focus our analysis on two strong blooms that occurred in late May 2001 in the Loire and Gironde plumes. We performed different assimilation experiments for the period from May, $12^{\text {th }}$ to June $5^{\text {th }}$; fifteen clear SeaWiFS images were available, and the field cruise PEL01 track went through each plume.

We use the KORR routine of Schwefel (1995) to minimize the cost function. As other Evolutionary Algorithms (EA), this is a stochastic zero ${ }^{\text {th }}$ order method (i.e., requiring only values of the function to optimize) that can find the global minimum of very rough non-linear functions. These algorithms are based on the principle of self-adaptation of a population of individuals (the sets of parameters), with respect to their fitness (the cost function). For that, the population undergoes iterative mutations, recombinations and selections. The mutation, which is the main operator in ES, is applied to individuals by adding a zero-mean Gaussian variable of standard deviation $\sigma$ to their parameters. Recombination allows for exchanging information between individuals. Selection is a deterministic process, based on the value of the cost function of all individuals of a population, that lets the best individuals for the next generation. One of the powerful paradigms of ES as compared with other EA is the self-adaptation of strategy parameters of the mutation $(\sigma)$ which undergo mutation as well. 
Depending on the standard deviation applied at the beginning, and its later evolution during optimization, the search can be done in the whole parameter space of real numbers. However this is not worth doing so, as we have often prior information on different parameters useful to reduce the search space, and so the computation time. This avoids also finding a minimum for the cost function corresponding to unrealistic parameters. This is obvious, for instance, for negative values, which are impossible for all our parameters by their physical nature. Therefore we apply a transformation to our parameters, so that the search is assessed between two defined bounds for each parameter. If $\mathrm{P}$ is a given parameter value, $P_{0}$ and $P_{1}$ its lower and upper bounds, and $P^{*}$ its prior value, then this gives for the new defined $P^{\prime}$ value :

$$
\begin{array}{ll}
P^{\prime}=\left(P-P^{*}\right) /\left(P_{1}-P\right) & \text { if } P>P^{*} \\
P^{\prime}=\left(P-P^{*}\right) /\left(P-P_{0}\right) & \text { if } P<P^{*}
\end{array}
$$

Moreover, with this transformation, the search space is now centered on zero, and the Gaussian-type search becomes more relevant. The lower bounds are all set to zero. The upper bounds are defined depending on the reliability we have on a priori parameter values.

The misfit function $J_{d}$ is a measure of the misfit between the model solution (C), run with the set of parameter values $\mathrm{p}$, and the available satellite clear pixels (c) :

$$
J_{d}=\sum_{i}^{n} \frac{(\ln (C(p))-\ln (c))^{2}}{n}
$$

with $\mathrm{n}$ the number of clear pixels used in the misfit calculation. The result of the optimization will depend on the formulation of the misfit. There are numerous possible formulations for it (Evans, 2003), and one has to select an appropriate one depending on data and priorities. In our case, we have only one variable and unit used in the misfit, so we have no scaling problems between different variables. The values of the chlorophyll $a$ observations range over several orders of magnitude in coastal areas where strong blooms may occur. The observation errors from satellite data are roughly proportional to the magnitude of the observations. To take into account this error in the optimization, the misfit is calculated on logarithmic transformed data.

We add to this model-data misfit a parameter misfit based, as in Evans (1999) and Dadou et al. (2004), on the deviation from any previous knowledge we might have on each parameter, and on the bounds between which the parameters are allowed to vary. So we use the transformation of Eq.1 giving $P^{\prime}$ to define this new misfit function $J_{p}$ :

$$
J_{p}=\frac{w}{N_{p}} \sum_{i}^{N_{p}}\left(P^{\prime}\right)^{2}
$$


with $N_{p}$ the number of control parameters. The weight $w$ serves to put both misfits on a common scale, so that $J_{p}$ takes a significant value as compared to $J_{d}$, only when $\mathrm{P}$ is close to its bounds. A value of 0.01 gives for a parameter estimate halfway between target and bounds a misfit corresponding to an error of $10 \%$ in the model-data retrieval.

In the real data assimilation experiment, the cost function is the sum of $J_{d}$ and $J_{p}$. Twin experiments are also conducted to test the efficiency of the method in the recovery of a known set of parameters. In these experiments, daily chlorophyll $a$ maps simulating SeaWiFS data are computed by the model with the reference set of parameters. Then, this data fully consistent with the model, serves as assimilated data to recover the reference set of parameters from a randomly perturbed one. As our global optimization method should be able to recover the minimum corresponding to the reference set of parameters, when searching in the whole prescribed parameter space, the parameter misfit constraint $J_{p}$ was not added in these experiments.

\subsection{Sensitivity analysis on parameters}

Optimizing our biological parameters (approximately fifty) all together is not feasible nor appropriate. First, the confidency we have on their values can be very different, from the commonly used Redfield ratio to the very poorly known mortality rates. Second, some of the model components may be negligible at some times of the year, like dinoflagellates during the winter and spring blooms. As a result, all related parameters cannot be constrained through the optimization process. Last, many model parameters are highly correlated, based on the strong non-linearities inherent to biogeochemical models. For these different reasons, one may reduce significantly the number of control parameters.

We thus conduct a sensitivity analysis to assess the most sensitive parameters through their influence on the different state variables, and to gather the correlated parameters. We follow the general sensitivity analysis used in Friedrichs (2001) and Garcia-Gorriz et al. (2003), and apply it to our assimilation period of the end of May 2001. The sensitivity of a model component $\mathrm{C}$ to a given parameter $\mathrm{P}$ is defined as the fractional change in $\mathrm{C}$ due to a fractional increase in the value of $\mathrm{P}$ :

$$
S_{C, P}=\frac{\frac{C_{P}-C_{P \%}}{C_{P \%}}}{\frac{P-P \%}{P \%}}
$$

in which $P \%$ refers to the reference value of the parameter modified by a fractional of this value. Phosphate was the first limiting nutrient during the blooms of May 2001, as given by the model and confirmed by in situ data (see 
Fig.5 as compared to the Redfield N:P ratio). Therefore we focus our analyses on the following components : Chlorophyll $a(\mathrm{Chl})$, derived from diatoms, and for a negligible part during this season from dinoflagellates, Zooplankton $(\mathrm{Zoo})$, Phosphate $\left(\mathrm{PO}_{4}\right)$, and Detrital Phosphorus $\left(P_{D e t}\right)$. As we assimilate only surface chlorophyll concentration data, we measure the influence of the parameters on the surface concentration of the latter components.

\section{Results and discussion}

\subsection{Modelling of the winter bloom}

\subsubsection{Comparison of the model outputs with in situ and satellite data}

The role of SPM is illustrated in the initiation of the late winter 2001 bloom over the Bay of Biscay. The field cruise NUTRIGAS captured the bloom. Spatial distribution of salinity in the surface layer (Fig.6a) reveals a large extension of the Loire and Vilaine plume in relation to the high river flow observed during January and the beginning of February 2001 (Fig.7a,b). The surface chlorophyll a concentrations (Fig.6b) show values of more than $4 \mathrm{mg} . \mathrm{m}^{-3}$ South-West of Belle-Ile, in the distal part of the Loire plume. From the results of the CTD casts performed along a NNW-SSW transect (between February, $24^{\text {th }}$ and February, $28^{\text {th }}$ 2001), it appeared that a strong haline stratification was established in the upper layer (Fig.8a). The corresponding section has been drawn from the model outputs for a given date of the observation period. The model stratification agrees with observations, even if its offshore extension seems more limited by deepening of isohalines in the distal part of the plume (Fig.8b). The chlorophyll maximum was distributed in the surface layer offshore (Fig.8c), and was related to particles of size ranging from 20 to $70 \mu m$ (PSA measurements), visible on total SPM section of figure 8e. Microscopic observations carried out on surface samples confirmed an abundance of diatoms of large size (Thalassiosira, Shroderella) typically found in late winter blooms in the Bay of Biscay (Herbland et al., 1998; Labry et al., 2001; Gohin et al., 2003). Conversely, low chlorophyll $a$ was measured in the bottom layer and closer to the coast where total SPM estimated from the PSA show values higher than $5 \mathrm{~g} \cdot \mathrm{m}^{-3}$ (Fig.8e). This abundance of non-fluorescent particles increased dramatically in the Loire mouth. Microscopic observations confirmed the abundance of sedimentary particles, which origin can be both river supply and resuspension. This particle distribution is well reproduced with the model SPM concentration (Fig.8f), with somehow lower concentrations where organic part of SPM is non negligible, i.e. in the chlorophyll maximum offshore and within the Loire mouth. This is explained by the slight overestimation of the weight estimation from the PSA in case of organic particles (Lunven and 
Gentien, 2000), and because model SPM does not consider living particles. The chlorophyll $a$ section from the model (Fig.8d) differs from the observations in the location of the highest values. This has to be moderated by the fact that the bloom observed offshore during the field cruise rapidly extended in the direction of the coast, as detailed in the validation below.

Fig.9 displays the estimated map of surface chlorophyll $a$ concentrations in February from SeaWiFS, and from two model simulations. The SeaWiFS mean images show the initiation of the bloom over the major part of the shelf with highest values between 3 and $10 \mathrm{mg} \cdot \mathrm{m}^{-3}$ at the end of February. Lowest values are found in the most turbid coastal areas (estuaries, around Oleron Island). The first simulation maps (Fig.9(2)), that consider the SeaWiFS SPM forcing, agree well with SeaWiFS (Fig.9(1)) in the timing of the bloom initiation and its location. Chlorophyll $a$ values are underestimated along the southern coast of the Bay of Biscay. The proximity of strong bathymetry gradients in this part of the Bay may explain the greater difficulty to well simulate the dynamics and therefore the phytoplankton production. Chlorophyll $a$ values are overestimated in the Bay of Vilaine at the end of February (Fig.9(2c)). For comparison, Fig.9(3) shows the results of a simulation without taking into account the SPM light attenuation. In this case, the bloom occurs from the beginning of February in shallow coastal areas, and during mid-February over the main part of the shelf.

\subsubsection{A theoretical validation}

These results can be validated by the theoretical minimum depth average irradiance $E_{m}$ necessary for the initiation of a bloom, following Riley (1957). This calculation requires the total sea surface solar irradiance $\left(E_{0}\right)$, the depth $Z_{m}$ of the mixed-layer, in which the phytoplankton population is considered homogeneous, and the extinction coefficient $K_{P A R}$ :

$$
E_{m}=\frac{E_{0}\left(1-e^{-K_{P A R} Z_{m}}\right)}{K_{P A R} Z_{m}}
$$

All of these requirements are either forcing data $\left(E_{0}\right)$ or calculated variables of our model $\left(Z_{m}, K_{P A R}\right)$. The calculation is done for both model simulations, for an area in the distal part of the Loire plume for the first three months of the year 2001. Fig.10 shows these results as compared with the minimum value for $E_{m}$ of $20.9 \mathrm{~W} \cdot \mathrm{m}^{-2}$ proposed by Riley (1957). This minimum has proven to be appropriate for the Bay of Biscay (Morin et al., 1991; Labry et al., 2001; Gohin et al., 2003). We consider that the bloom is initiated after a few days when $E_{0}$ becomes higher than the minimum required. In the case of the normal simulation, this condition is observed in the last ten days of February, whereas in the simulation without SPM this is observed as early as the $10^{\text {th }}$. These results confirm the initiation dates of the blooms observed in 
this area on Fig. $9(2 b, 3 b)$.

The date of the bloom initiation reproduced with the model in the Bay of Biscay agrees both with satellite information and in situ data in the north of the Bay. Concerning this area, the bloom begins in the distal part of the plume, south of Belle-Ile. In this area, the haline stratification together with low SPM concentration, as given by data and reproduced by the model, give adequate blooming conditions at the end of February, in the Riley's sense. Conversely, the coastal part of the Loire plume is too turbid for enabling a significant phytoplankton growth, even if the stratification is stronger. This interpretation can be extended to the Gironde plume. This analysis shows the strong sensitivity of the bloom initiation to both SPM concentration and depth of the mixed-layer. A slight error on one of these variables could partly explain why the bloom maximum location in the model may not be in full agreement with the cruise observation of the maximum chlorophyll $a$ concentrations. But one has to remind that the field observation is instantaneous, and that evolution of the bloom location may have changed within a few days. The SeaWiFS images give a synoptic view of this evolution, and seem to confirm the expansion of the bloom on a wider area.

\subsection{Biological parameters for the bloom of May 2001}

\subsubsection{Hydrological features during the blooms}

The field cruise PEL01 sampled the Gironde plume between 20 and 25 May, and Loire plume in early June, and so captured the bloom distribution in both areas (Fig.11). The SeaWiFS images of the optimization areas (Fig.12 and 13, top) reveal that the cruise probably did not capture the highest chlorophyll $a$ concentrations of the blooms, especially for the Loire plume which shows very high concentrations on May, 29 $9^{t h}$. After this date, the chlorophyll concentration decreases in the plumes, and the June $10^{\text {th }}$ image (not shown) confirms the termination of the bloom. Strong river discharges during spring with two maxima at $4000 \mathrm{~m}^{3} \cdot \mathrm{s}^{-1}$ around the April $1^{\text {st }}$ and at the beginning of May for the Loire (Fig.7a), and values around $2000 \mathrm{~m}^{3} \cdot \mathrm{s}^{-1}$ during spring until the beginning of May for the Gironde (Fig.7c) make the year 2001 a particular one. Consequently, salinity is less than 35 in the surface waters of the whole shelf, and stratification is really strong in the river plumes, as given by the transect performed in three days in each plume (Fig.14a,b). Same sections from the model (Fig.14c,d), for given dates corresponding to the observation periods of both transects, are in good agreement with field data which is a prerequisite for our study. Indeed, an incorrect hydrological model situation would have constrained our biological parameter optimization to correct both biological and physical features. 


\subsubsection{Results of the sensitivity analysis}

The results of the sensitivity analysis for a fractional variation of $+25 \%$ are given in Table 4, for both Loire and Gironde blooms. We did the same analysis for a variation of $-25 \%$, which gave close results. Only parameters with a sensitivity $S_{C}>0.005$ are presented. From this, all parameters related to Dinoflagellates are removed. Also stoichiometric ratios are not considered here, even if Chlorophyll/Nitrogen ratio can be highly variable depending on ecological conditions. Finally, the attenuation coefficients related to different optical active components were considered fixed and reliable since they were already optimized for the Bay of Biscay (Gohin et al., 2005). The phosphorus river loads have been added to the analysis, as they have high associated uncertainties and could be influent on primary production.

The different parameters have been gathered in Table 4, by looking at the sensitivity of the four state variables chosen through the $\mathrm{S}_{C, P}$ values (sign and amplitude). Sinking rate parameters for diatoms have a similar behaviour, with sensitivities to $W_{\min }$ having approximately the same values than sensitivities to $w$ in the Loire and Gironde cases, and sensitivities to $W_{\max }$ being twice as high. Looking at the zooplankton coefficients, $\mu_{Z o o}^{0}$ and $\gamma$ show a strong proportional effect, while $m_{Z o o}^{0}$ and $m_{Z o o / B i o m}$ can also be gathered. $\tau_{\text {assimil }}$ can be associated with the former zooplankton group even if its effect on zooplankton $\left(S_{Z o o}\right)$ is higher. The sensitivities to $W_{\text {det }}$ for phytoplankton and zooplankton look similar, with low values, except for the sensitivity of $P_{\text {det }}$ especially to $W_{d e t}^{z o o}$. Parameters related to $\mathrm{P}$ availability have similar effects $\left(C_{d e s}\right.$, river phosphorus loads, with an opposite proportional behaviour for $\left.k_{a d s}^{\max }\right)$. The coefficient $\operatorname{rmin}_{P_{\text {eau }}}^{0}$, which shows different effects, especially on $P_{\text {det }}$ has been put in the last group of Table 4, which gathers parameters that can not be associated one to another, neither with previously constituted groups.

One striking result from Table 4 is that all $\mathrm{S}_{C, P}$ whatever $\mathrm{C}$ and $\mathrm{P}$ behave similarly in the Loire and Gironde river plumes, which allows us to use the same control parameters for the later optimization. From this table, the control parameters were selected as follows : only one parameter of the correlated groups defined before is kept, with preferency for parameters with the highest absolute values of $S_{C, P}$, and particularly of $S_{C h l, P}$ as chlorophyll is the assimilated data. This gives the following three parameters : $W_{\max }, \mu_{Z o o}^{0}$ and $m_{Z o o}^{0}$. No parameter is considered for groups with low influence, that is the group with $W_{\text {det }}$ and the $\mathrm{P}$ availability group. Within the last group, we kept the highest influent parameters, giving $\mu_{\text {Diat }}^{0}$ and $m_{\text {Diat }}^{0} . r m i n_{P_{\text {eau }}}^{0}$ is added to the control parameters. It has little effect with respect to the $+25 \%$ variation sensitivity analysis. However, considering the possibility of higher variations for the different parameters during the optimization process, $\mathrm{P}$ is likely to become a strongly limiting factor, with $\operatorname{rmin}_{P_{\text {eau }}}^{0}$ becoming a central parameter. 
This sensitivity analysis confirms that the influence of the different parameters is very difficult to assess intuitively, and consequently tuning manually such parameters can often have a non expected effect. For instance, increasing the growth rate of diatoms reduces the mean biomass on the simulated period. This proves the usefulness of an optimization approach.

\subsubsection{Twin experiments}

Results for both areas are presented in Table 5. The prescribed bounds have been set very large (between zero and five times the reference value). For some of the parameters this authorized range can give unrealistic values. However, in the context of twin experiments, this will assess the efficiency of our global optimization method.

For both experiments on the Loire and Gironde plumes, the cost function at the end of the optimization process reaches a very small value $(\approx 3 \%$ of mean relative error). Looking at the other variables from the model outputs (nutrients, zooplankton, detritic organic matter), differences between the reference and the optimized run for different depths are negligible as well. Optimized parameter values can be compared with reference values. Some of the estimated values have converged very close to the reference parameters values (less than $10 \%$ of relative error), and the continuation of the process would have certainly led to smaller errors. For the parameters with higher errors, rmin ${ }_{\text {Peau }}^{0}$ and $m_{Z o o}^{0}$ in both experiments, they seem to converge to other values. These values are always within $\pm 50 \%$ of the reference value, which is a realistic range. The weak sensitivity of the cost function to these parameters can explain the difficulty to retrieve their reference value. This does not mean that the search for a minimum is stucked in a local one, which is normally avoided with the ES, but the parameter value has rather converged towards a value among others in a large 'valley' containing the reference value. These twin experiments show the efficiency of Evolutive Strategies in retrieving a global minimum for our problem, within a wide parameter space.

\subsubsection{Real SeaWiFS data assimilation}

Fig.12 and 13 show the model-estimated surface chlorophyll $a$ concentration for the Loire and Gironde optimization areas, respectively. In each case, the model run before (middle) and after (bottom) optimization is compared with the SeaWiFS given situation for the same dates. These comparison dates are chosen so that they cover the bloom period, and coincide with availability of clear SeaWiFS images. In both cases, the run with first guess parameters underestimates the intensity and extension of the bloom. The chlorophyll concentration is quite homogeneous along the bloom period, with maximum values 
around 7-8 mg. $\mathrm{m}^{-3}$ and $3 \mathrm{mg} \cdot \mathrm{m}^{-3}$ close to the Loire and Gironde estuary, respectively. This run underestimates concentrations outside of the plumes with values lower than $0.2 \mathrm{mg} \cdot \mathrm{m}^{-3}$ as compared with values of SeaWiFS between 1 and $2 \mathrm{mg} \cdot \mathrm{m}^{-3}$. The run with optimized parameters increases chlorophyll $a$ estimated concentrations over the whole area, leading to a better fit between model and SeaWiFS derived data.

In the Loire plume (Fig.12), the extension of the bloom is better simulated, with high values as early as May $21^{s t}$ in the Bay of Vilaine, and maximum values close to $10 \mathrm{mg} \cdot \mathrm{m}^{-3}$ on May $29^{t h}$. However, the maximum values observed by SeaWiFS are still underestimated by the model, whereas values along the southern coast seem to be overestimated for the whole period. In the Gironde plume (Fig.13), the extension of the bloom along the southern coast is improved. Offshore concentrations agree with SeaWiFS data. Highest concentrations observed on the first two SeaWiFS images are underestimated.

Fig.15 shows the behaviour of the optimization process, in the Loire experiment, with parameter values converging and cost function decreasing over the iterations. The optimization is stabilized over 3000/5000 iterations for the Loire and Gironde plumes, respectively. Looking at the SeaWiFS images on Fig.12, the optimization will try to get a fast bloom development and a fast bloom decline. For the fast bloom development, and with the control parameters we kept, having more surface chlorophyll a concentrations implies decreasing phytoplankton mortality and sinking rate, reducing zooplankton grazing pressure (by reducing $\mu_{Z o o}^{0}$ and increasing $m_{Z o o}^{0}$ ), and increasing the phosphorus mineralisation rate to fuel the primary production. One would also expect an increase of phytoplankton growth rate, but results of sensitivity analysis (Table 4) already suggested the contrary. For the fast bloom decline, the way sinking rate is parameterized cannot handle a fast response. It depends on the nutrient limitation term to simulate the increase in sinking rate of deficient cells, often under an aggregation effect. $\mathrm{P}$ mineralisation was pretty active while $\mathrm{W}_{\max }$ underwent a decrease to accommodate bloom development, so the time shift between nutrient limitation and sinking rate increase may not allow the fast bloom decline.

Table 6 gives the optimized parameter and cost function values before and after optimization. For both experiments, the final cost is less than half the initial one. The strong bloom with high variability in the Loire plume may explain the higher misfit in this area. Comparing the set of optimized parameters, four among six have comparable values between Loire and Gironde plumes. Only $\mu_{\text {Diat }}^{0}$ and $\mu_{Z o o}^{0}$ for the Gironde are more than twice those for the Loire. This can be explained by the difference in phytoplankton structure between the two areas, as observed from the size fractionation. In the Loire plume, diatoms (size $>20 \mu \mathrm{m}$ ) are fully representative of the bloom, whereas picophytoplankton ( $\operatorname{size}<3 \mu \mathrm{m}$ ) community is representative only of $10 \%$ of 
the biomass. In the Gironde plume, picophytoplankton and nanophytoplankton (latter of size between 3 and $20 \mu \mathrm{m}$ ) represents $20-40 \%$ and $50-70 \%$ of the biomass, respectively. Following Labry et al. (2002), this observation may be explained by a sooner nutrient limitation in the Gironde plume, leading to a preferency for small species growth. Pico and nanophytoplankton have higher growth rates than diatoms, so the optimization may tend to compensate for the absence of the small phytoplankton group in the model.

The fact that the optimization changes parameter values in a similar way would mean that the initial parameter set contains errors constant over different areas and maybe also periods of time. To test this hypothesis, we computed a mean parameter set from those obtained in both areas, and tested it over the entire year 2001. The simulated chlorophyll $a$ concentrations were highly overestimated over the whole year. This confirms that our estimated parameter set is valid under particular conditions typical to the spring bloom in the large plumes of the Bay of Biscay.

The time scale of the order of the month chosen for the optimization is greater than the typical time scale of a bloom. Thus bloom-related processes can be improved by our estimated parameter set. This is not the case for processes with longer time scale, that cannot be correctly retrieved unless the optimization period is modified. Our sensitivity analysis has normally eliminated these parameters from the selection. Short time scale variability in biological responses to environmental changes may be more annoying, as seen before with parameterization of sinking rate of diatoms.

\section{Conclusions}

Satellite 'ocean color' data over the Bay of Biscay have been used to constrain a 3D phytoplankton production model from winter to spring 2001. Late winter blooms are strongly light-limited, and depend on both the depth of the mixed-layer and the SPM concentration, the latter increasing the coefficient of light attenuation. Using satellite SPM has proven to be useful to simulate the initiation of late winter blooms. This is the case for the February 2001 bloom, for which we had several available images.

In this context, future work is clearly needed to improve the model of sediment transport at the scale of the shelf. One needs to know accurate parameterizations of processes such as deposition, the wave effect on resuspension, or sediment compaction as well as the composition and quality (particle size and nature) of the sediments. Information such as higher frequency river supply of particles is also required. Once a fully comprehensive model of sediment transport will be validated, a more complex assimilation scheme for SPM could be 
used to consider the remaining errors in the model of sediment transport.

Parameter calibration is a key step in any ecosystem analysis. This can be achieved along several routes. One is done by testing parameter values from the literature, and then by adjusting them with comparison of the model outputs to data. This can be done when phytoplankton production is only sensitive to a few parameters with simple correlations. This is the case in February, when light is the only limiting factor. During the blooms of May, multiple or co-limitations are possible, and so tuning parameters can become a complex issue, with unexpected effects on the model behaviour to parameter changes as seen in the sensitivity analysis. In this case, the use of a global optimization routine solving non-linear interactions between parameters allows to automatically adjust parameter values. The phytoplankton blooms of May are thus better simulated. For our optimization period, some of the parameter values had little influence on the state variables. For other periods of the year, the sensitivity analysis would show different results, allowing for another selection of control parameters. Thus the optimization could be performed at different periods for the optimization of the whole set of parameters.

Remaining errors may find different explanations, related to the complexity of coastal systems modelling. First, some biological processes may not be included in the model, preventing us to well reproduce the observed variability. Second, the fastness in the changing peculiarities of the coastal ecosystem (species, their responses and adaptations to the environment) cannot be taken into account in our model through changes in parameter values. This has been evidenced with two different values retrieved for growth rates depending on the location of the bloom. In this context, the formulation of the model can be improved through parameter sensitivity and optimization studies, here the pico-nanophytoplankton component could be added to better simulate phytoplanktonic production over different conditions in the Bay of Biscay. Last, even if the hydrodynamic model is forced with high resolution meteorological data, the simulated physical fields remain an approximation of reality. The strong dependency of biology on hydrodynamics may explain some of the unsolved errors.

The effect of data error on model results was not investigated in this work. The effort was rather put on the methodology. Therefore we considered the data as 'perfect', even if a formulation of data error was introduced in the cost function. Friedrichs (2001) and Garcia-Gorriz et al. (2003), in case of twin experiments, showed that data error, but also data resolution, have important effects on optimized parameters. Knowing that 'ocean color' data in coastal areas contain numerous errors, their effects on parameter estimation, but also on light modelling, should be considered in future work. However, in the selected situations, the satellite-derived chlorophyll was consistent with observations and showed coherent spatial and temporal patterns. However, 
considering model errors in assimilation, which is possible with weak constraint methods (Natvik et al., 2001; Losa et al., 2004), is also a necessary issue in an operational context.

Our experiments lead to the conclusion that one optimal parameter set for a given period is not appropriate for the entire seasonal phytoplankton production. Because the seasonal time scale is an objective of such biogeochemical models, and because the non-continuous switch between different sets of parameters is not a solution, new approaches have to be investigated. Among them, filters allowing sequential adjustment of parameter values are an issue (Losa et al., 2003). Arhonditsis and Brett (2004) also present the use of goal functions as an approach to simulate the adaptation of the model to environmental changes.

\section{Acknowledgements}

This study was funded part by CNES and IFREMER with a fellowship support to M. Huret, by an ACI 'Observation de la Terre' grant to LEGOS, by the national program 'PNEC-Chantier Golfe de Gascogne' and IFREMER program 'Défi Golfe de Gascogne'. The authors would like to thank the SeaWiFS Project and the Distributed Active Archive Center at the Goddard Space Flight Center, Greenbelt, MD 20771, for the production and distribution of the SeaWiFS data acquired at the Dundee station. We are indebted also to NASA for providing the SeaDAS software. We are extremely grateful to METEO-FRANCE, for the METEOSAT data provided through SATMOS (Service d'Archivage et de Traitement Météorologique des Observations Spatiales) and the SAF (Satellite Application Facility project) Ocean and Ice of EUMETSAT, in Lannion, as well as for the meteorological models ARPEGE and ALADIN data supply. The in situ data were plotted with ODV (Schlitzer, R., Ocean Data View, http://www.awi-bremerhaven.de/GEO/ODV, 2004). We thank the Loire-Brittany and Adour-Garonne water Agencies for river hydrological data supply. We thank P. Lazure for providing the MARS3D code, F. Dumas and P. Cugier for its coupling with a first version of the biogeochemical model, and S. Loyer for her preliminary modelling work over the Bay of Biscay. We thank I. Dadou (LEGOS) for her useful advices on the use of the optimization routine KORR. We also thank A. Ménesguen and J.-F. Guillaud for critical reading of this manuscript and useful discussions, as well as the two anonymous reviewers for their useful and constructive comments . 


\section{Appendix A}

\section{Equations of the biogeochemical model}

$$
\begin{aligned}
& \frac{d \mathrm{NO}_{3}}{d t}=\text { rnit }_{\text {Neau }} \times \mathrm{NH}_{4}-r_{N O_{3}}^{\text {Diat }} \times \mu_{\text {Diat }} \times \text { Diat }-r_{N O_{3}}^{\text {Dino }} \times \mu_{\text {Dino }} \times \text { Dino } \\
& \frac{d \mathrm{NH}_{4}}{d t}=\operatorname{rmin}_{N e a u} \times \mathrm{N}_{\text {det }}-\text { rnit }_{\text {eau }} \times \mathrm{NH}_{4}-r_{N H_{4}}^{\text {Diat }} \times \mu_{\text {Diat }} \times \text { Diat } \\
& -r_{N H_{4}}^{\text {Dino }} \times \mu_{\text {Dino }} \times \text { Dino }+E_{z o o} \times \frac{\text { Zoo }}{12 \times r_{C: N}^{Z o o}} \\
& \frac{d \mathrm{Si}}{d t}=\operatorname{rdis}_{\text {Sieau }} \times \mathrm{Si}_{\mathrm{det}}-r_{\text {Si:N }}^{P h y} \times \mu_{\text {Diat }} \times \text { Diat } \\
& \frac{d \mathrm{PO}_{4}}{d t}=-k_{a d s} \times \mathrm{PO}_{4}+k_{d e s} \times \mathrm{Pads}+r m i n_{\text {Peau }} \times \mathrm{P}_{\text {det }} \\
& -r_{P: N}^{P h y} \times\left(\mu_{\text {Diat }} \times \text { Diat }+\mu_{\text {Dino }} \times \text { Dino }\right)+E_{z o o} \times \frac{\text { Zoo }}{12} \times \frac{r_{P: N}^{Z o o}}{r_{C: N}^{Z o o}} \\
& \frac{d \mathrm{Pads}}{d t}=k_{a d s} \times \mathrm{PO}_{4}-k_{d e s} \times \mathrm{Pads} \\
& \frac{d \text { Diat }}{d t}=\left(\mu_{\text {Diat }}-m_{\text {Diat }}\right) \times \text { Diat }-g r_{\text {Diat }} \times \frac{\text { Zoo }}{12 \times r_{C: N}^{Z o o}}-W_{\text {Diat }} \frac{d \text { Diat }}{d z} \\
& \frac{d \text { Dino }}{d t}=\left(\mu_{\text {Dino }}-m_{\text {Dino }}\right) \times \text { Dino }-g r_{\text {Dino }} \times \frac{\text { Zoo }}{12 \times r_{C: N}^{Z o o}} \\
& \frac{d \text { Zoo }}{d t}=\left(\tau_{\text {assimil }} \times \mu_{Z o o}-E_{Z o o}-m_{Z o o}\right) \times Z_{\circ o} \\
& \frac{d \mathrm{~N}_{\text {det }}}{d t}=m_{\text {Diat }} \times \text { Diat }+m_{\text {Dino }} \times \text { Dino }-r m i n_{N e a u} \times \mathrm{N}_{\text {det }} \\
& +\left(m_{Z o o}+\left(1-\tau_{\text {assimil }}\right) \times \mu_{Z o o}\right) \times \frac{Z_{o o}}{12 \times r_{C: N}^{Z o o}}-W_{D e t} \frac{d \mathrm{~N}_{\mathrm{det}}}{d z} \\
& \frac{d \mathrm{Si}_{\mathrm{det}}}{d t}=r_{\text {Si:N }}^{P h y} \times m_{\text {Diat }} \times \text { Diat }-r d i s_{\text {Sieau }} \times \mathrm{Si}_{\mathrm{det}} \\
& +g r_{\text {Diat }} \times \frac{\text { Zoo }}{12} \times \frac{r_{S i: N}^{P h y}}{r_{C: N}^{Z o o}}-W_{D e t} \frac{d S_{i_{d e t}}}{d z} \\
& \frac{d \mathrm{P}_{\text {det }}}{d t}=r_{P: N}^{P h y} \times\left(m_{\text {Diat }} \times \text { Diat }+m_{\text {Dino }} \times \text { Dino }\right)-r m i n_{\text {Peau }} \times \mathrm{P}_{\text {det }} \\
& +\left(m_{Z o o}+\left(1-\tau_{\text {assimil }}\right) \times \mu_{Z o o}\right) \times \frac{Z o o}{12} \times \frac{r_{P: N}^{P h y}}{r_{C: N}^{Z o o}}-W_{D e t} \frac{d P_{\text {det }}}{d z}
\end{aligned}
$$




\section{Appendix B}

\section{Phytoplankton}

Growth rate : $\mu=\mu^{0} \times f_{T} \times f_{\text {lim }}$

Diatoms : $f_{\text {lim }}=\min \left(f_{\text {lum }}, f_{N}, f_{S i}, f_{P}\right)$

Dinoflagellates : $f_{\text {lim }}=\min \left(f_{\text {lum }}, f_{N}, f_{P}\right)$

Light limitation (After Steele (1962)) :

$f_{\text {lum }}=\frac{1}{\Delta z} \int_{z}^{z+\Delta z}\left(\frac{I_{z}}{I_{\text {opt }}}\right) \times \exp { }^{\left(1-\frac{I_{z}}{I_{o p t}}\right)} d z$

Nutrients limitation : $f_{S N}=\frac{S N}{S N+K_{S N}}$

For nitrogen : $f_{N}=\frac{\mathrm{NO}_{3} / K_{N 0_{3}}+\mathrm{NH}_{4} / K_{N H_{4}}}{1+\mathrm{NO}_{3} / K_{N 0_{3}}+\mathrm{NH}_{4} / K_{N H_{4}}}$

with $r_{N H_{4}}=\frac{f_{N H_{4}}}{f_{N}}$ and $r_{N O_{3}}=\frac{f_{N O_{3}}}{f_{N}}$

Temperature limitation : $f_{T}=e x p^{(a \times T)}$

$a=0.07 ; Q_{10}=2$ (After Eppley (1972))

Mortality : $m=m^{0} \times f_{T}$

\section{Zooplankton}

Growth rate (Ivlev formulation):

$\mu_{Z o o}=\mu_{Z o o}^{0} \times f_{T} \times\left(1-\exp \left(-\gamma \times \max \left(0, \frac{\left(p_{\text {Diat }} \times \text { Diat }+p_{\text {Dino }} \times \text { Dino }\right) \times r_{C: N}}{r_{C: C h l}}\right)-P_{0}\right)\right.$ with $p_{\text {Diat }}$ and $p_{\text {Dino }}$ preferency coefficients for Diatoms and Dinoflagellates $g r_{\text {Diat }}=\frac{\mu_{Z_{o o} \times p_{\text {Diat }} \times \text { Diat }}}{p_{\text {Diat }} \times \text { Diat }+p_{\text {Dino }} \times \text { Dino }}$ and $g r_{\text {Dino }}=\frac{\mu_{Z_{o o}} \times p_{\text {Dino }} \times \text { Dino }}{p_{\text {Diat }} \times \text { Diat }+p_{\text {Dino }} \times \text { Dino }}$

Mortality : $m_{Z o o}=f_{T} \times \max \left(m_{Z o o}^{0}, m_{Z o o / B i o m} \times\right.$ Zoo $)$

Excretion : $\epsilon=\epsilon^{0} \times f_{T}$

\section{Mineralisation}

$\operatorname{rmin}_{\text {eau }}=\operatorname{rmin}_{\text {eau }}^{0} \times f_{T}$ and $\operatorname{rmin}_{\text {sed }}=\operatorname{rmin}_{\text {sed }}^{0} \times f_{T}$

rnit $_{\text {eau }}=$ rnit $_{\text {eau }}^{0} \times f_{T}$ and rnit $_{\text {sed }}=$ rnit $_{\text {sed }}^{0} \times f_{T}$

\section{Sinking rates}

Diatoms : $W_{\text {Diat }}=W_{\text {min }} \times$ fstress $_{\text {Diat }}+W_{\text {max }} \times\left(1-\right.$ fstress $\left._{\text {Diat }}\right)$

with stress $_{\text {Diat }}=\left(f_{S N}^{\text {Diat }}\right)^{w}$

Particulate organic matter :

$W_{\text {Det }}=W_{\text {Det }}^{z o o} \times \frac{1}{r+1}+W_{\text {Det }}^{\text {phy }} \times\left(1-\frac{1}{r+1}\right)$

with $r=\frac{m_{\text {Diat }} \times \text { Diat }+m_{\text {Dino }} \times \text { Dino }}{\left(\left(1-\tau_{\text {assimil }}\right) \times \mu_{\text {Zoo }}+m_{\text {Zoo }}\right) \times \text { Zoo }}$

Adsorption-Desorption of phosphate

$k_{a d s}=C_{a d s} \times \max \left(0, k_{a d s}^{\max } \times \mathrm{SPM}-\right.$ Pads $)$

$k_{\text {des }}=C_{\text {des }} \times \min \left(1, \frac{\text { Pads }}{k_{\text {ads }}^{\max } \times \mathrm{SPM}}\right)$ 


\section{Appendix C}

\section{Light availability modelling}

The light availability for photosynthesis at $\operatorname{depth} z$ is obtained by :

$$
I(z, t)=P A R \times I_{0}(t) \exp ^{-\int_{0}^{z} K_{P A R}(z) d z}
$$

where $P A R=0.425$ (Jitts et al., 1976) converts incident surface irradiance $I_{0}$ to photosynthetically active radiation. $K_{P A R}$ is expressed as a combination of chlorophyll and SPM (Gohin et al., 2005) :

$$
K_{P A R}=k_{w}+k_{p} \times C h l^{0.8}+k_{s p m} \times S P M
$$

with $k_{w}=0.1, k_{p}=0.05$ and $k_{s p m}=0.0625$. We could have used the $K_{P A R}$ directly deduced from chlorophyll $a$ and SPM concentrations from SeaWiFS. However, to be consistent with the model variable, we recalculate this quantity in the model. Chlorophyll $a$ is deduced from the phytoplankton components (diatoms and dinoflagellates) assuming a Carbon:Chlorophyll mass ratio of 50. SPM is a combination of the SPM model state variable corrected with SeaWiFS SPM data.

As explained in section 2.2, this correction is of particular interest during the winter season. However, winter presents the highest cloud cover, which strongly limits image availability. Rather than using a climatology that would not be appropriate with respect to the high observed interannual variability, we interpolate between our clear SeaWiFS images of the year 2001 to have a continuous daily information.

After missing data areas (no more than 5 pixels $\approx 5 \mathrm{~km}$ ) have been filled by linear interpolation, we use the kriging method to interpolate in time. This means that we have more confidence in the time covariance of the SPM variable than in its space covariance when cloudy areas become large. For the objective interpolation, SPM at location $\mathrm{X}(\mathrm{x}, \mathrm{y})$ and date $\mathrm{t}$ is considered as a random variable, called $\mathrm{SPM}_{s a t}$. To describe the temporal structure of SPM, we build the time autocovariance function Cov between all SPM clear pixels from our SeaWiFS database (1998-2003). We here consider that the mean $\mathrm{m}$ of $\mathrm{SPM}_{\text {sat }}$ is dependent on X. We calculate for each pair of pixels (n pairs) separated by a distance $\mathrm{t}$ in day :

$$
\operatorname{Cov}(t)=\sum_{i=1}^{n} \frac{\left[S P M_{s a t}\left(X_{i}, t_{i}+t\right)-m\left(X_{i}\right)\right]\left[S P M_{s a t}\left(X_{i}, t_{i}\right)-m\left(X_{i}\right)\right]}{n}
$$

The experimental autocovariance is given in Fig.4. As time increases, the covariance between pairs of pixels decreases. $\sigma^{2}$, the apparent jump of the covariance at the origin, known in geostatistics as the 'nugget', can be seen as the variance of the noise associated to SPM at one pixel location. It can 
be related to estimation errors, or microscale space and time variability. The periodicity visible on the experimental covariance shows a spring/neap tide time lag, revealing the influence of this cycle on resuspension and/or mixing processes increasing surface SPM concentration. This effect is not considered here, but should be further investigated if SPM time resolution has to be improved. After the covariance signal has been filtered, a function is fitted, to be used in the interpolation between clear images.

To obtain the concentration for a location at a given date, we consider the nearest four clear images (2 before and 2 after with a limit of one month), searching for the best linear unbiased estimator. This estimator $S P M_{\text {sat }}^{*}(X, t)$ is obtained from the kriging system :

$$
S P M_{\text {sat }}^{*}(X, t)=\sum_{i=1}^{4} \lambda_{i} S P M_{\text {sat }}\left(X, t_{i}\right)
$$

$\lambda_{i}$ are such that $\operatorname{Mean}\left(S P M_{\text {sat }}^{*}(X, t)\right)=S P M_{\text {sat }}(X, t)$ and $\operatorname{Var}\left(S P M_{\text {sat }}^{*}(X, t)-\right.$ $\left.S P M_{\text {sat }}(X, t)\right)$ is minimal.

In the kriging hypothesis, $\operatorname{Var}\left(S P M_{\text {sat }}^{*}(X, t)-S P M_{\text {sat }}(X, t)\right)$ is calculated from the covariance Cov (Armstrong, 1998).

The SPM variable correction in the model is done once a day. As surface and bottom SPM concentrations are often weakly correlated, an inverse exponential function of depth is used to weight the SeaWiFS SPM forcing. Considering a background concentration $\operatorname{SPM}_{b}(X, z, t)$ of the model at depth $z$ and time $\mathrm{t}$, this gives a new concentration $\operatorname{SPM}(X, z, t)$ as following :

$$
S P M(X, z, t)=S P M_{b}(X, z, t)+\left(S P M_{\text {sat }}^{*}(X, t)-S P M_{b}(X, z, t)\right) \exp ^{-\alpha \times z}
$$

A value of 0.03 is chosen for $\alpha$, which gives a small influence of $\mathrm{SPM}_{\text {sat }}$ under a depth of 30 meters, typical of the haline stratification layer of the Bay of Biscay. Most of the time, as the model underestimates the SPM resuspension, the effect of the correction is adding SPM to the water column. 


\section{References}

Arhonditsis, G. B., Brett, M. T., 2004. Evaluation of the current state of mechanistic aquatic biogeochemical modeling. Mar. Ecol. Prog. Ser. 271, $13-26$.

Armstrong, M., 1998. Basic Linear Geostatistics. Springer, Berlin, 153p.

Athias, V., Mazzega, P., Jeandel, C., 2000. Selecting a global optimization method to estimate the oceanic particle cycling rate constant. J. Mar. Res. 58 (5), 675-707.

Bäck, T., 1996. Evolution strategies: An alternative evolutionary algorithm. In: Artificial Evolution 94-95 : The book. Springer-Verlag, pp. 3-20.

Brisson, A., Le Borgne, P., Marsouin, A., 2001. Ice SAF Surface Solar Irradiance Product Manual, Version 1. Météo-France/DP/CMS, Lannion.

Brisson, A., Le Borgne, P., Marsouin, A., Moreau, T., 1994. Surface irradiance calculated from Meteosat sensor during SOFIA-ASTEX. Int. J. Remote Sens. 15, 197-203.

Carder, K. L., Hawes, D. K., Baker, K. A., Smith, R. C., Steward, R. G., Mitchell, B. G., 1991. Reflectance model for quantifying chlorophyll a in the presence of productivity degradation products. J. Geophys. Res. 96, 20 599-20 611.

Carmillet, V., Brankart, J. M., Brasseur, P., Drange, H., Evensen, G., Verron, J., 2001. A singular evolutive extended Kalman filter to assimilate ocean color data in a coupled physical-biochemical model of the North Atlantic ocean. Ocean Modelling 3, 167-192.

Cugier, P., Le Hir, P., 2000. Modélisation 3D des matières en suspension en Baie de Seine orientale (Manche, France). C. R. Acad. Sci. Paris 331, $287-$ 294.

Cugier, P., Ménesguen, A., Guillaud, J.-F., 2004. Three dimensional (3D) ecological modelling of the Bay of Seine (English Channel, France). J. Sea Res. In press.

Dadou, I., Evans, G., Garçon, V., 2004. Using JGOFS in situ and ocean colour data to compare biogeochemical models and estimate their parameters in the subtropical North Atlantic ocean. J. Mar. Res. 62 (4), 565-594.

Denman, K., 2003. Modelling planktonic ecosystems: parameterizing complexity. Progr. Oceanogr. 57, 429-452.

Eppley, R. W., 1972. Temperature and phytoplankton growth in the sea. Fish. Bull. 70 (4), 1063-1085.

Evans, G. T., 1999. The role of local models and data sets in the Joint Global Ocean Flux Study. Deep-Sea Res. I 46, 1369-1389.

Evans, G. T., 2003. Defining misfit between biogeochemical models and data sets. J. Mar. Syst. 40-41, 49-54.

Fasham, M. J. R., Ducklow, H. W., McKelvie, S. M., 1995. The use of optimization techniques to model marine ecosystem dynamics at the JGOFS station at $47^{\circ} \mathrm{N} 20^{\circ} \mathrm{W}$. Philos. Trans. R. Soc. Lond. B (348), 203-209.

Faugeras, B., Lévy, M., Mémery, L., Verron, J., Blum, J., Charpentier, I., 
2003. Can biogeochemical fluxes be recovered from nitrate and chlorophyll data ? A case study assimilating data in the Northwestern Mediterranean Sea at the JGOFS-DYFAMED station. J. Mar. Syst. 40-41, 99-125.

Fennel, K., Losch, M., Schröter, J., Wenzel, M., 2001. Testing a marine ecosystem model : sensitivity analysis and parameter optimization. J. Mar. Syst. 28, 45-63.

Friedrichs, M. A. M., 2001. A data assimilative marine ecosystem model of the central equatorial Pacific : Numerical twin experiments. J. Mar. Res. 59, 859-894.

Friedrichs, M. A. M., 2002. Assimilation of JGOFS EqPac and SeaWiFS data into a marine ecosystem model of the central equatorial Pacific Ocean. DeepSea Res. II 49, 289-319.

Froidefond, J. M., Lavender, S., Laborde, P., Herbland, A., Lafon, V., 2002. SeaWiFS data interpretation in a coastal area in the Bay of Biscay. Int. J. Remote Sens. 23 (5), 881-904.

Garcia-Gorriz, E., Hoepffner, N., Ouberdous, M., 2003. Assimilation of SeaWiFS data in a coupled physical-biological model of the Adriatic sea. J. Mar. Syst. 40-41, 233-252.

Gentien, P., Lunven, M., Le Haitre, M., Duvent, J.-L., 1995. In situ depth profiling of particle sizes. Deep Sea Res. 42, 1297-1312.

Gohin, F., Druon, J. N., Lampert, L., 2002. A five channel chlorophyll concentration algorithm applied to SeaWiFS data processed by SeaDAS in coastal waters. Int. J. Remote Sens. 23 (8), 1639-1661.

Gohin, F., Lampert, L., Guillaud, J. F., Herbland, A., Nézan, E., 2003. Satellite and in-situ observations of a late winter phytoplankton bloom in the northern Bay of Biscay. Cont. Shelf Res. 23, 1117-1141.

Gohin, F., Loyer, S., Lunven, M., Labry, C., Froidefond, J. M., Delmas, D., Huret, M., Herbland, A., 2005. Satellite-derived parameters for biological modelling in coastal waters : illustration over the eastern continental shelf of the Bay of Biscay. Remote Sens. Environ. 95, 29-46.

Gunson, J., Oschlies, A., Garçon, V., 1999. Sensitivity of ecosystem parameters to simulated satellite ocean color data using a coupled physical-biological model of the North Atlantic. J. Mar. Res. 57, 613-639.

Hemmings, J. C. P., Srokosz, M. A., Chellenor, P., Fasham, M. J. R., 2003. Assimilating satellite ocean-colour observations into oceanic ecosystem models. Phil. Trans. R. Soc. Lond. A Series A, Mathematical, Physical and Engineering Sciences (361), 33-39.

Herbland, A., Delmas, D., Laborde, P., Sautour, B., Artigas, F., 1998. Phytoplankton spring bloom of the Gironde plume waters in the Bay of Biscay : early phosphorus limitation and food-web consequences. Oceanol. Acta 21 (2), 279-291.

Hofmann, E. E., Friedrichs, M. A. M., 2001. Models : biogeochemical data assimilation. In: M.J.R.Fasham, J.H.Steele, S., K.Turekian (Eds.), Encyclopedia of Ocean Sciences. Vol. 1. Academic Press, London, pp. 302-308.

Holm-Hansen, O., Lorenzen, C. J., Holmes, R. W., Strickland, J. D. H., 1965. 
Fluorometric determination of chlorophyll. J. Cons. Perm. Int. Explor. Mer $30,3-15$.

Huret, M., Dadou, I., Dumas, F., Lazure, P., Garçon, V., 2005. Coupling physical and biogeochemical processes in the Río de la Plata plume. Cont. Shelf Res. 25, 629-653.

Hurtt, G. C., Armstrong, R. A., 1996. A pelagic ecosystem model calibrated with BATS data. Deep-Sea Res. II 43, 625-651.

Ishizaka, I., 1990. Coupling of Coastal Zone Color Scanner data to a physicalbiological model of the Southeastern U.S. continental shelf ecosystem 3. nutrient and phytoplankton fluxes and CZCS data assimilation. J. Geophys. Res. 95 (C11), 20201-20212.

Jitts, H. R., Morel, A., Saijo, Y., 1976. The relation of oceanic primary production to available photosynthetic irradiance. Austral. J. Mar. Fresh. Res. 27, 441-454.

Kuroda, H., Kishi, M. J., 2004. A data assimilation technique applied to estimate parameters for the NEMURO marine ecosystem model. Ecological Modelling 172, 69-85.

Labry, C., Herbland, A., Delmas, D., 2002. The role of phosphorus on planktonic production of the Gironde plume waters in the Bay of Biscay. J. Plankton Res. 24 (2), 97-117.

Labry, C., Herbland, A., Delmas, D., Laborde, P., Lazure, P., Froidefond, J. M., Jegou, A. M., Sautour, B., 2001. Initiation of winter phytoplankton blooms within the Gironde plume waters in the Bay of Biscay. Mar. Ecol. Prog. Ser. 212, 117-130.

Lawson, L. M., Spitz, Y. H., Hofmann, E. E., Long, R. B., 1995. A data assimilation technique applied to predator-prey model. Bull. Math. Biol. 57, 593-617.

Lazure, P., Dumas, F., 2004. A 3D hydrodynamical model for applications at regional scale (MARS3D). Application to the Bay of Biscay. Ocean Modelling, submitted .

Lazure, P., Jegou, A.-M., 1998. 3D modelling of seasonal evolution of Loire and Gironde plumes on Biscay continental shelf. Oceanol. Acta 21 (2), 165-177.

Lefèvre, F., Lyard, F. H., Le Provost, C., Schrama, E. J. O., 2002. FES99 : A global tide finite element solution assimilating tide gauge and altimetric information. J. Atmos. Ocean. Technol. 19, 1345-1356.

Lellouche, J. M., Ouberdous, M., Eifler, W., 2000. 4D-var data assimilation system for a coupled physical-biological model. Proc. Indian. Acad. Sci. 109 (4), 491-502.

Losa, S. N., Kivman, G. A., Ryabchenko, V. A., 2004. Weak constraint parameter estimation for a simple ocean ecosystem model : what can we learn about the model and data ? J. Mar. Syst. 45, 1-20.

Losa, S. N., Kivman, G. A., Schröter, J., Wenzel, M., 2003. Sequential weak constraint parameter estimation in an ecosystem model. J. Mar. Syst. 43, 31-49.

Loyer, S., 2001. Modélisation de la production phytoplanctonique dans la zone 
côtière atlantique enrichie par les apports fluviaux. Ph.D. thesis, Université de Paris VI, 232 pp.

Loyer, S., Lazure, P., Gentien, P., Ménesguen, A., 2001. Modelling of Gymnodinium mikimotö̈ blooms along the French Atlantic coast : geographical and vertical distributions. Hydroécol. Appl. 1 (13), 57-76.

Lunven, M., Gentien, P., 2000. Suspended sediments in a macrotidal estuary : comparison and use of different sensors. Oceanol. Acta 23 (3), 245-259.

Matear, R. J., 1995. Parameter optimization and analysis of ecosystem models using simulated annealing: A case study at station P. J. Mar. Res. 53, 571607.

Morin, P., Le-Corre, P., Marty, Y., L’Helguen, S., 1991. Evolution printanière des éléments nutritifs et du phytoplancton sur le plateau continental armoricain (Europe du Nord-Ouest). Oceanol. Acta 14 (3), 263-279.

Natvik, L.-J., Eknes, M., Evensen, G., 2001. A weak constraint inverse for a zero dimensional marine ecosystem model. J. Mar. Syst. 28, 19-44.

Natvik, L.-J., Evensen, G., 2003. Assimilation of ocean colour data into a biochemical model of the North Atlantic Part 1. Data assimilation experiments. J. Mar. Syst. 40-41, 127-153.

O’Reilly, J. E., Maritorena, S., Mitchell, B. G., Siegel, D. A., Carder, K. L., Garver, S. A., Kahru, M., McClain, C., 1998. Ocean color chlorophyll algorithms for SeaWiFS. J. Geophys. Res. 103 (C11), 24,937-24,953.

Prunet, P., Minster, J. F., Ruiz-Pino, D., Dadou, I., 1996. Assimilation of surface data in a one-dimensional physical-biogeochemical model of the surface ocean 1. Method and preliminary results. Global Biogeochem. Cycles 10 (1), 111-138.

Redfield, A. C., Ketchum, B. H., Richards, F. A., 1963. The influence of organisms on the composition of sea water. In: Hill, M. N. (Ed.), The Sea. Vol. 2. Wiley Interscience, New-York, pp. 26-77.

Reynaud, T., Legrand, P., Mercier, H., Barnier, B., 1998. A new analysis of hydrographic data in the Atlantic and its application to an inverse modelling study. Int. WOCE Newsletter 32, 29-31.

Riley, G. A., 1957. Phytoplankton of the North Central Sargasso Sea, 1950-52. Limnology and Oceanography 2 (3), 252-270.

Schartau, M., Oschlies, A., 2003. Simultaneous data-based optimization of a 1D-ecosystem model at three locations in the North Atlantic: Part 1-Method and parameter estimates. J. Mar. Res. 61, 765-793.

Schartau, M., Oschlies, A., Willebrand, J., 2001. Parameter estimates of a zero-dimensional ecosystem model applying the adjoint method. Deep-Sea Res. II 48, 1769-1800.

Schwefel, H.-P., 1995. Evolution and Optimum Seeking. Sixth-Generation Computer Technology Series. John Wiley \& Sons, New York.

Spitz, Y. H., Moisan, J. R., Abbot, M. R., 2001. Configuring an ecosystem model using data from the Bermuda Atlantic Time Series (BATS). DeepSea Res. II 48, 1733-1768.

Spitz, Y. H., Moisan, J. R., Abbot, M. R., Richman, J. G., 1998. Data assim- 
ilation and a pelagic ecosystem model : parameterization using time series observations. J. Mar. Syst. 16, 51-68.

Steele, J. H., 1962. Environmental control of photosynthesis in the sea. Limnol. Oceanogr. 7 (2), 137-150.

Vallino, J. J., 2000. Improving marine ecosystem models : use of data assimilation and mesocosm experiments. J. Mar. Res. 58, 117-164. 


\section{List of Figures}

1 Bathymetry of the Bay of Biscay. The grey line delimits the model area.

2 The biogeochemical model.

3 January-February SPM composite from the years 1998-2003

SeaWiFS images. $100 \mathrm{~m}, 150 \mathrm{~m}$ and $1000 \mathrm{~m}$ isobaths are drawn.

4 Time covariance for the SPM from SeaWiFS images and fitted function (continuous line).

5 Surface N:P ratio from the PEL01 field cruise (30 April to 4 June 2001). Dots are station locations.

6 Surface salinity (a) and chlorophyll $a$ concentration (b) from NUTRIGAS field cruise (23 February to 1 March 2001). Dots are measurement locations. Transect on (a) is for sections of Fig.8.

7 Discharges of the Loire (a), Vilaine (b) and Gironde (c) rivers during the year 2001. Dotted lines delimit the periods of the NUTRIGAS and PEL01 field cruises.

8 Sections from the field cruise NUTRIGAS (23 February to 1 March 2001) (left) and from the model (right). Sections are from the transect of Fig.6a.

9 Ten days mean situations calculated from SeaWiFS images (1), outputs of the nominal model (2), and outputs of the model without SPM-derived light attenuation, for beginning (a), mid (b) and late (c) February 2001.

10 Daily mean irradiance in the surface mixel-layer $\left(E_{m}\right)$ calculated from Riley's equation and derived from METEOSAT surface irradiance data. Continuous/dashed line is the model case with SPM considered/not considered in $K_{P A R}$ calculation. Riley's critical value $\left(20.9 \mathrm{~W} . \mathrm{m}^{-2}\right)$ is also plotted.

11 Surface chlorophyll $a$ from the PEL01 cruise (30 April to 4 June 2001). Transects are for sections of Fig.14.

12 Surface chlorophyll $a$ in the Loire plume from SeaWiFS (top), the model before (middle) and after (bottom) parameter optimization. 
13 Surface chlorophyll $a$ in the Gironde plume from SeaWiFS (top), the model before (middle) and after (bottom) parameter optimization.

14 Salinity sections of the transects of Fig.11 from PEL01 cruise (a,b) and from the model $(\mathrm{c}, \mathrm{d})$. a,c and b,d are sections of the Loire and Gironde plume, respectively.

15 Evolution of parameter and cost function values along the optimization iterations for the Loire real SeaWiFS data experiment. Continuous lines indicate the first-guess value for each parameter.

\section{List of Tables}

1 List of parameter values for Phytoplankton and Zooplankton. NUT01 : NUTRIGAS field cruise (pers. com.) ; R63 : Redfield et al. (1963) ; C04 : Cugier et al. (2004) ; L01 : Loyer (2001) ; P01 : PEL01 field cruise (pers.com.).

2 List of sinking rate parameters. L01 : Loyer (2001).

3 List of parameters for particulate matter. C04 : Cugier et al. (2004).

4 Sensitivity values for a variation of $+25 \%$ on the model parameters. Only parameters with a sensitivity $S_{C}>0.005$ are given.

5 Parameter values for the twin experiments. For the estimated value, the relative error is indicated between parenthesis.

6 Parameter values for the real data experiments on the Loire $(\mathrm{L})$ and Gironde $(\mathrm{G})$ plumes. 


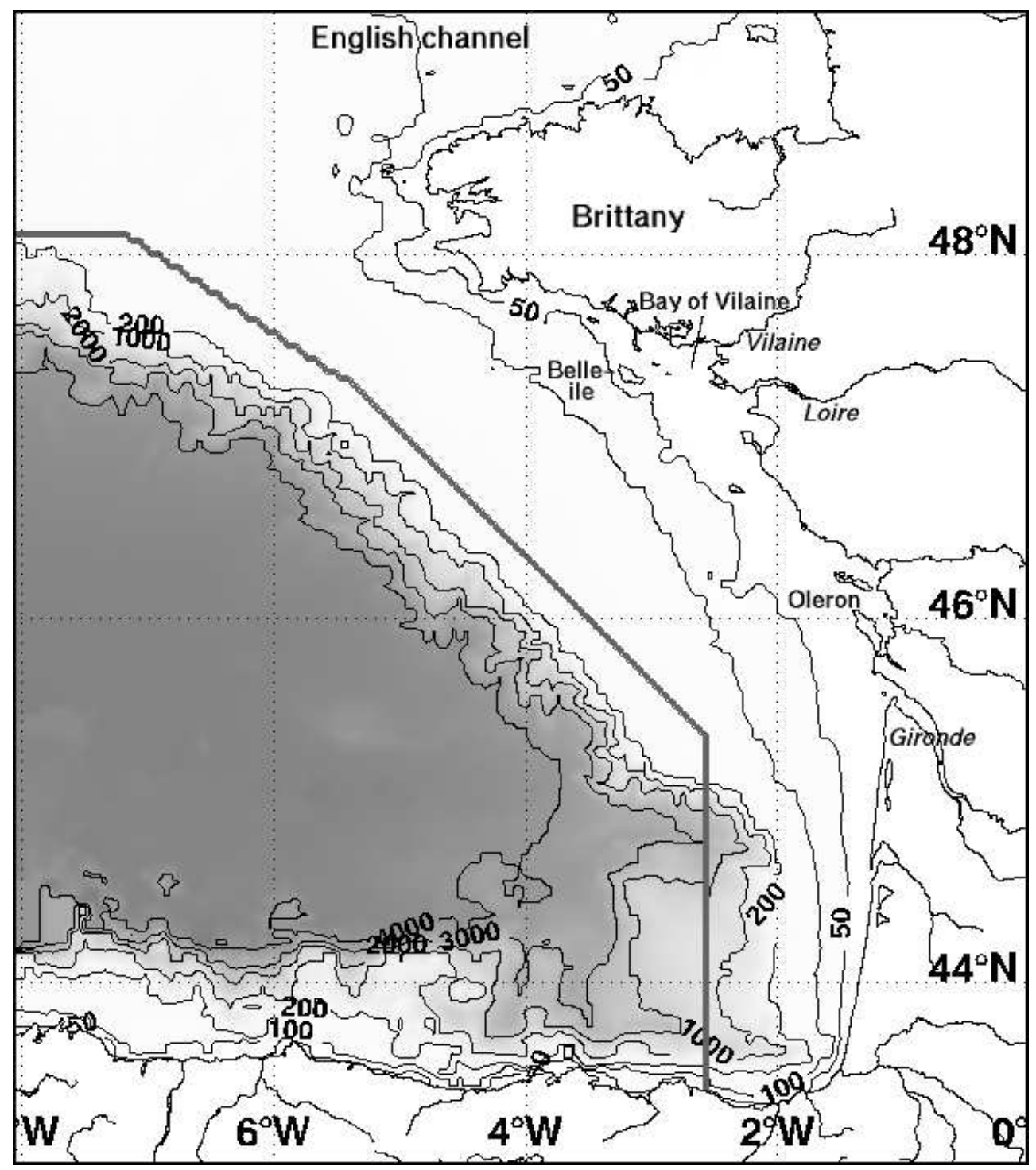

Fig. 1. Bathymetry of the Bay of Biscay. The grey line delimits the model area. 


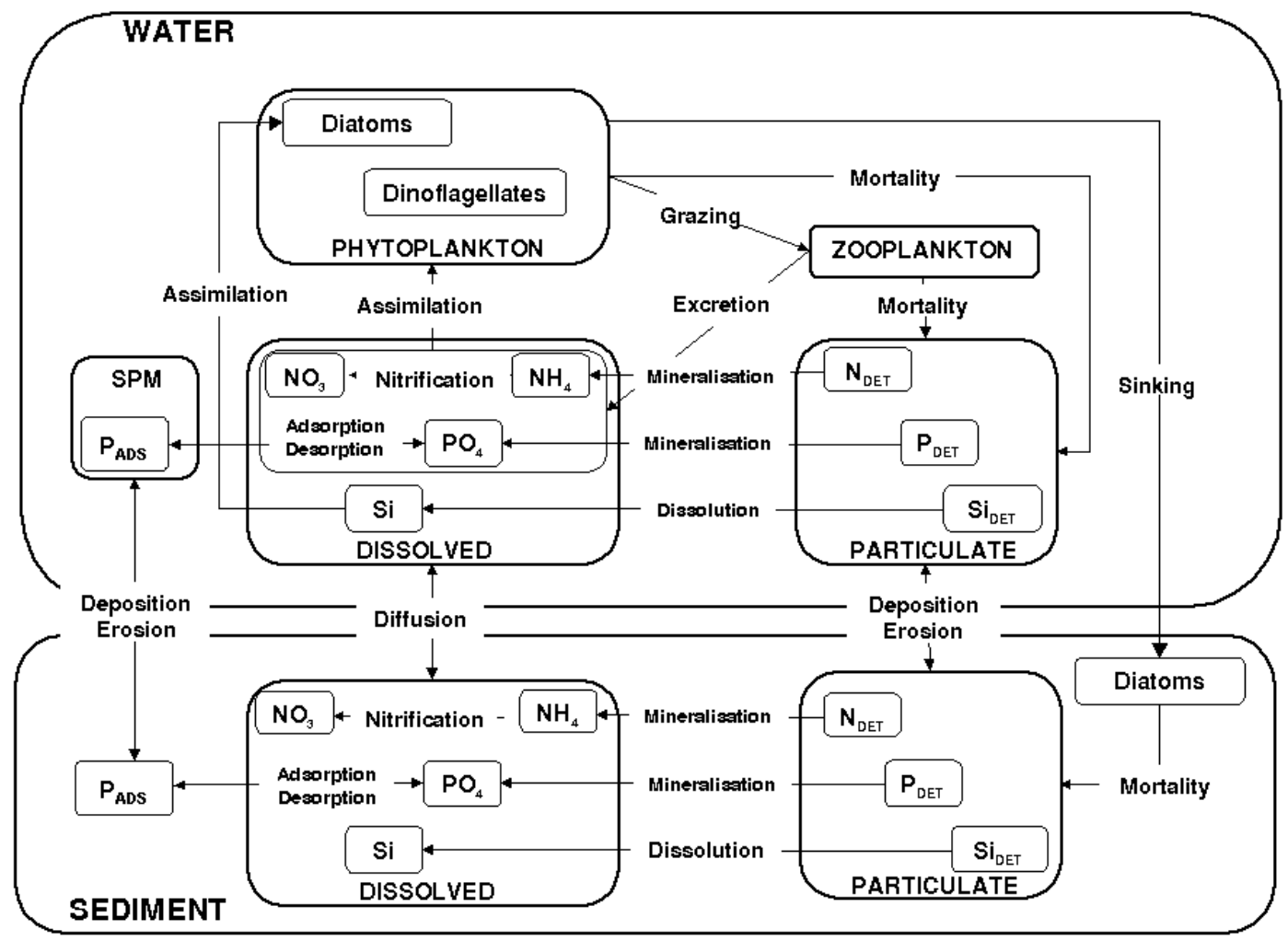

Fig. 2. The biogeochemical model. 


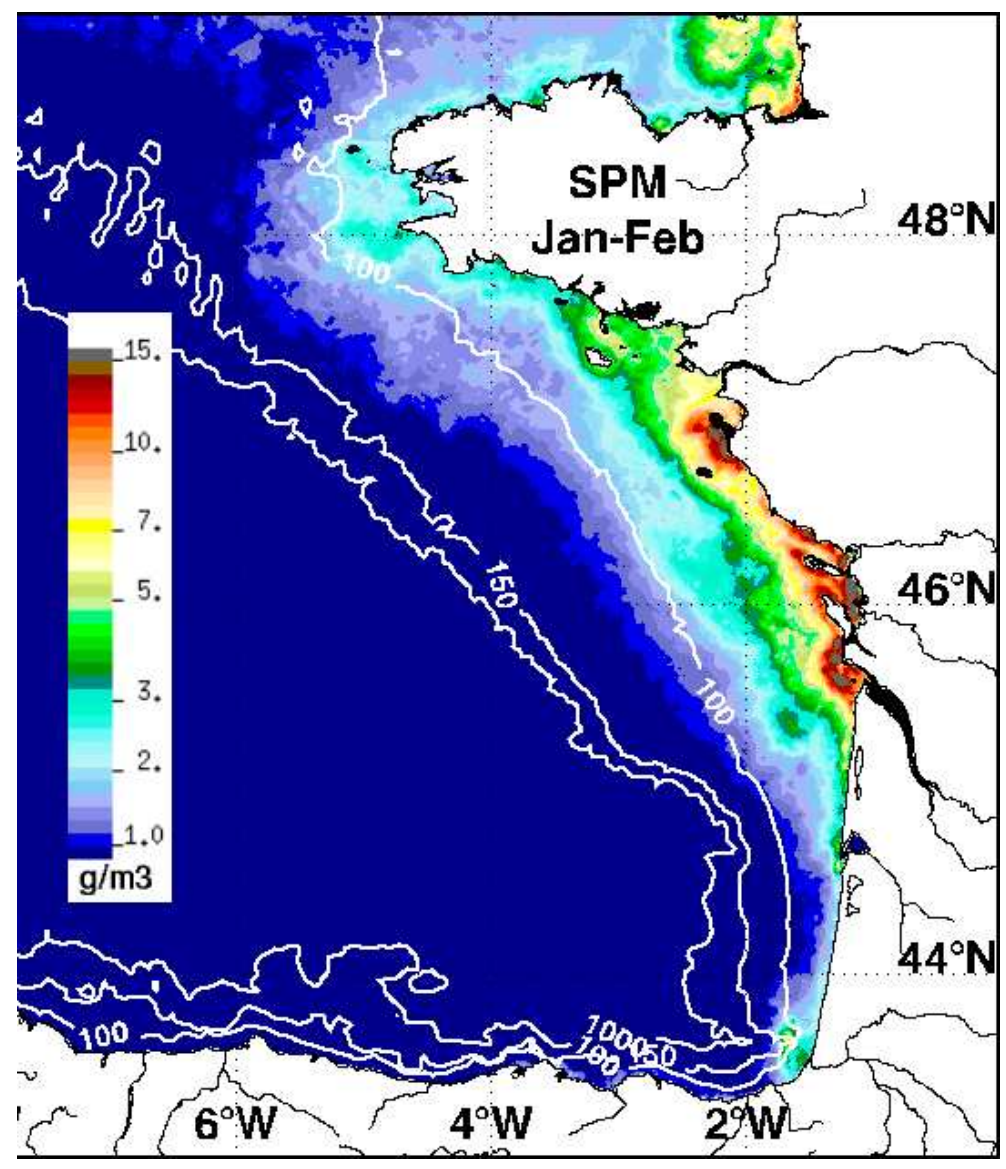

Fig. 3. January-February SPM composite from the years 1998-2003 SeaWiFS images. $100 \mathrm{~m}, 150 \mathrm{~m}$ and $1000 \mathrm{~m}$ isobaths are drawn. 


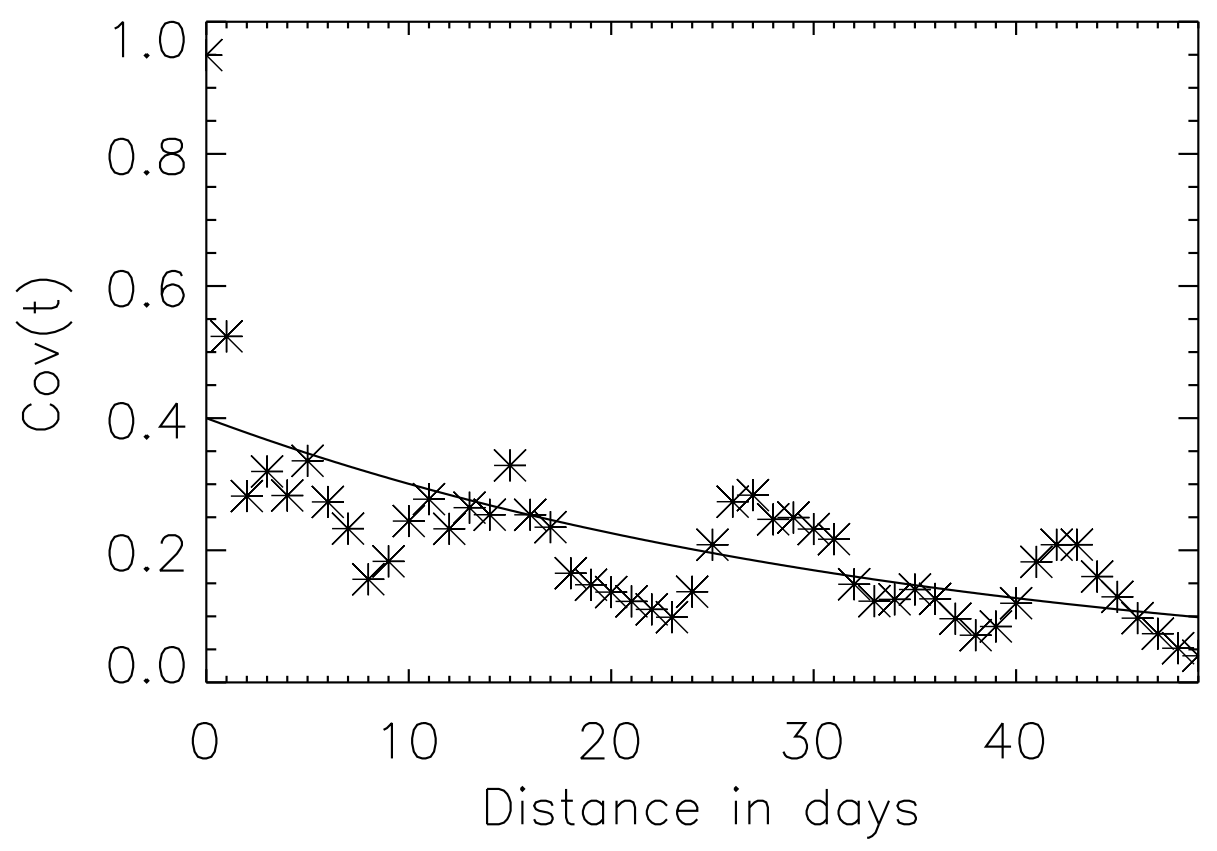

Fig. 4. Time covariance for the SPM from SeaWiFS images and fitted function (continuous line). 


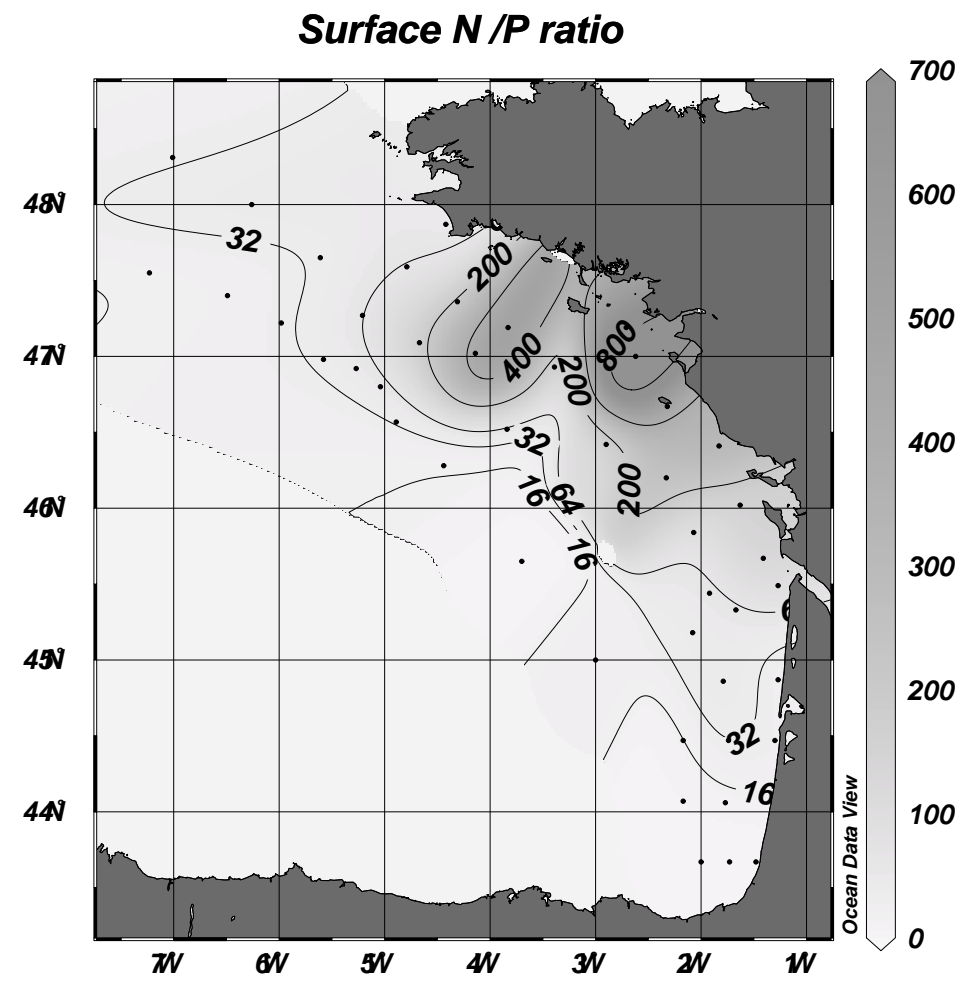

Fig. 5. Surface N:P ratio from the PEL01 field cruise (30 April to 4 June 2001). Dots are station locations. 
(a) Surface salinity



(b) Surface chlorophyll-a (mg. $\left.\mathrm{m}^{-3}\right)$

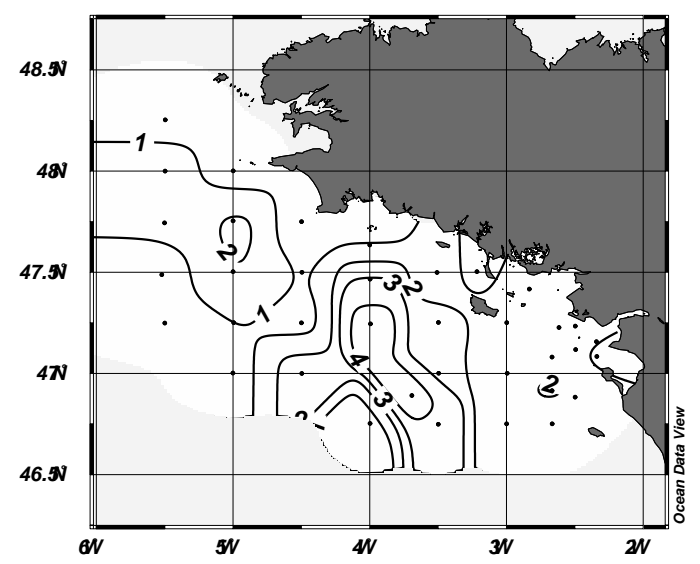

Fig. 6. Surface salinity (a) and chlorophyll $a$ concentration (b) from NUTRIGAS field cruise (23 February to 1 March 2001). Dots are measurement locations. Transect on (a) is for sections of Fig.8.
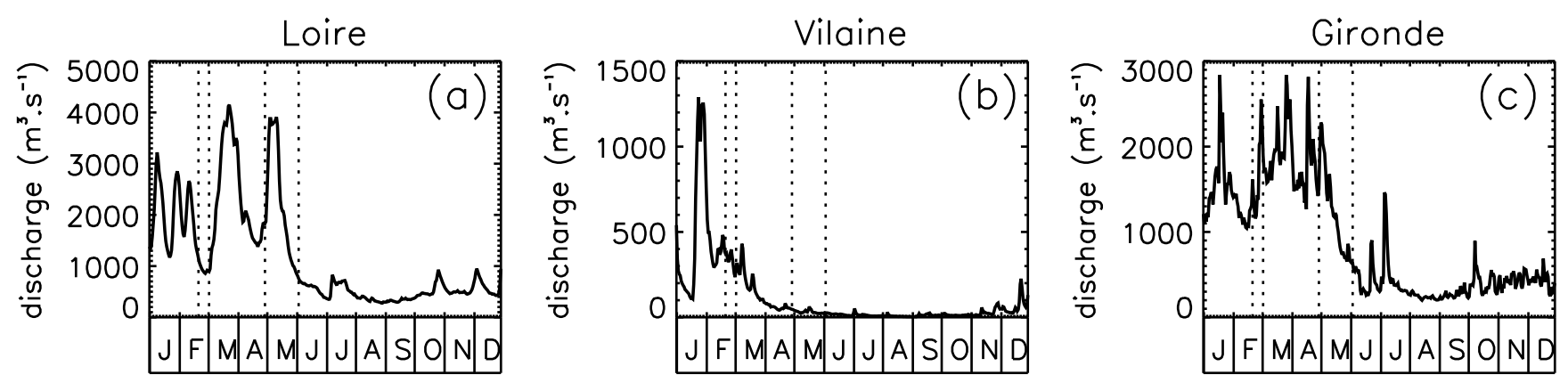

Fig. 7. Discharges of the Loire (a), Vilaine (b) and Gironde (c) rivers during the year 2001. Dotted lines delimit the periods of the NUTRIGAS and PEL01 field cruises. 


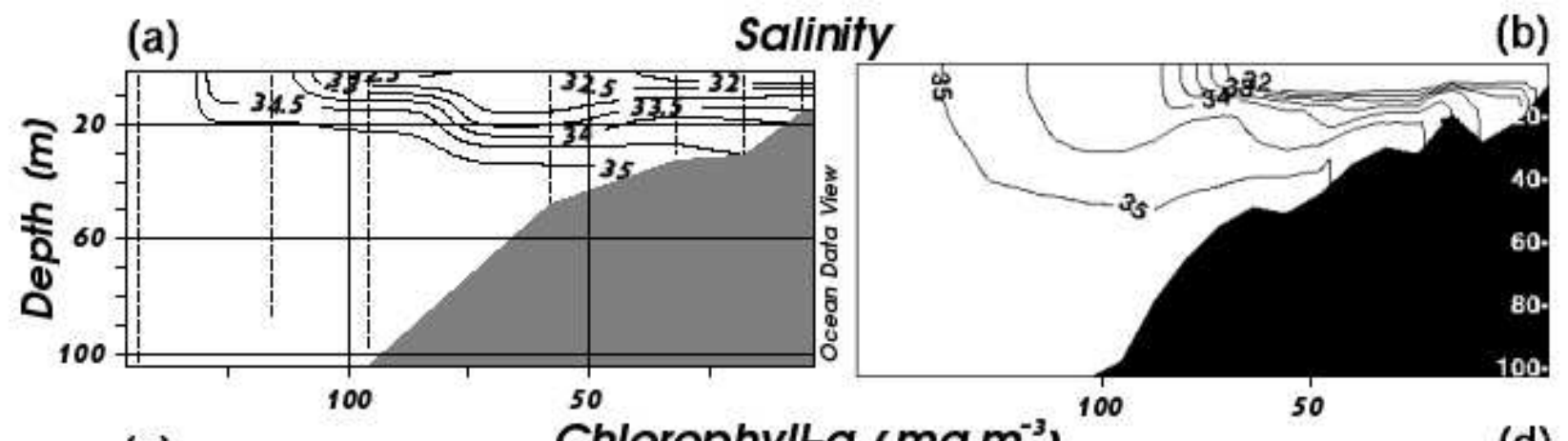

(c) Chlorophyll-a $\left(\mathrm{mg} \mathrm{m}^{-3}\right)$

(d)
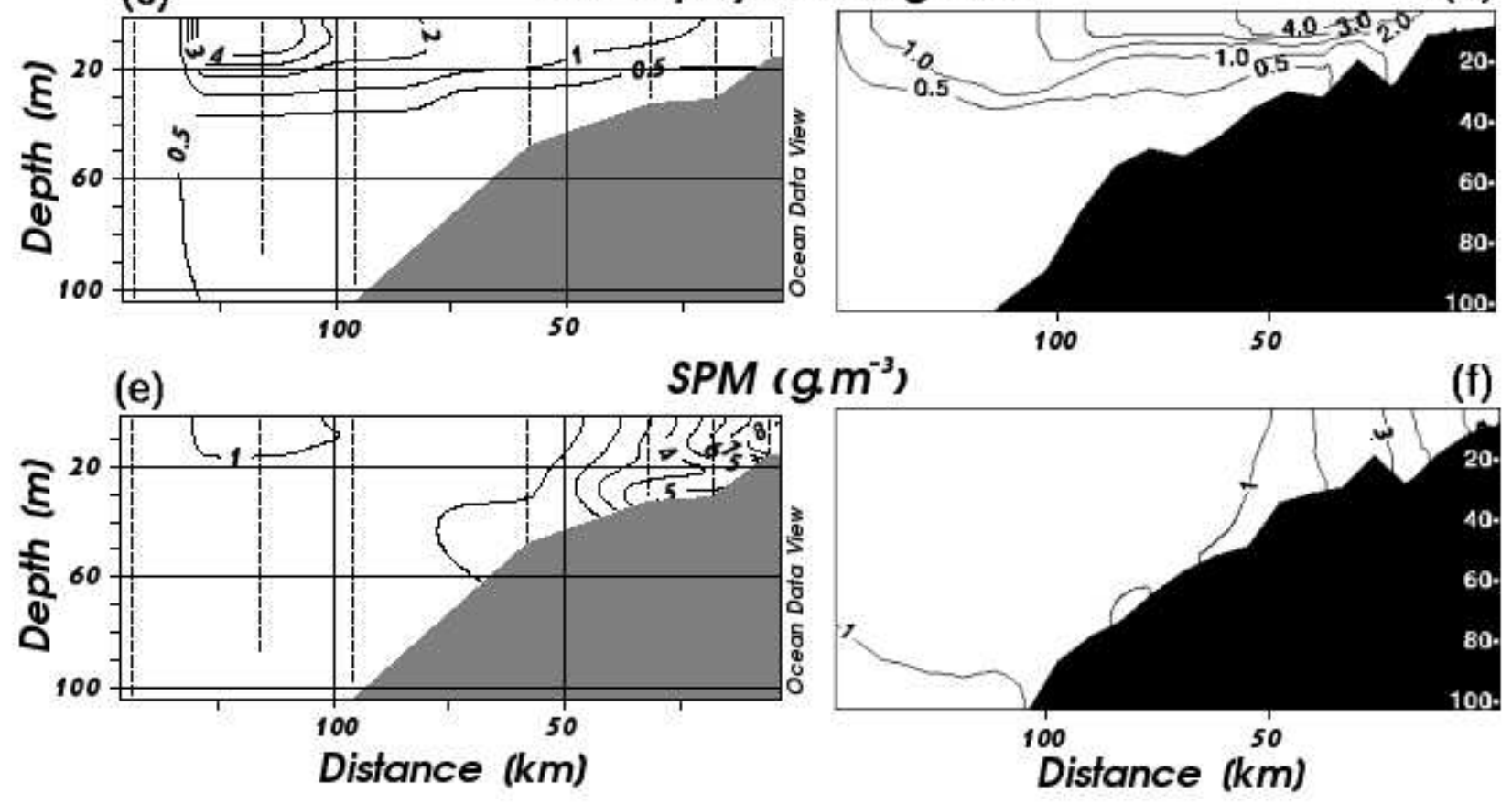

Fig. 8. Sections from the field cruise NUTRIGAS (23 February to 1 March 2001) (left) and from the model (right). Sections are from the transect of Fig.6a. 

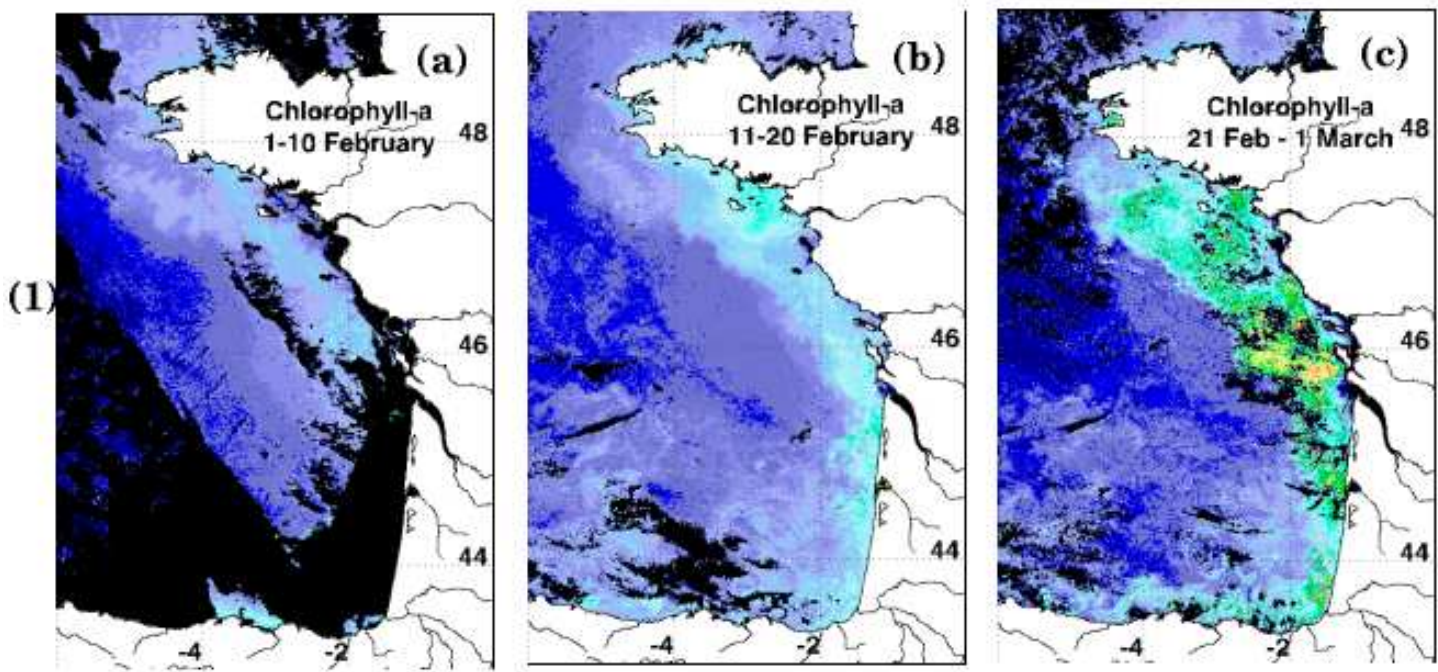

(2)
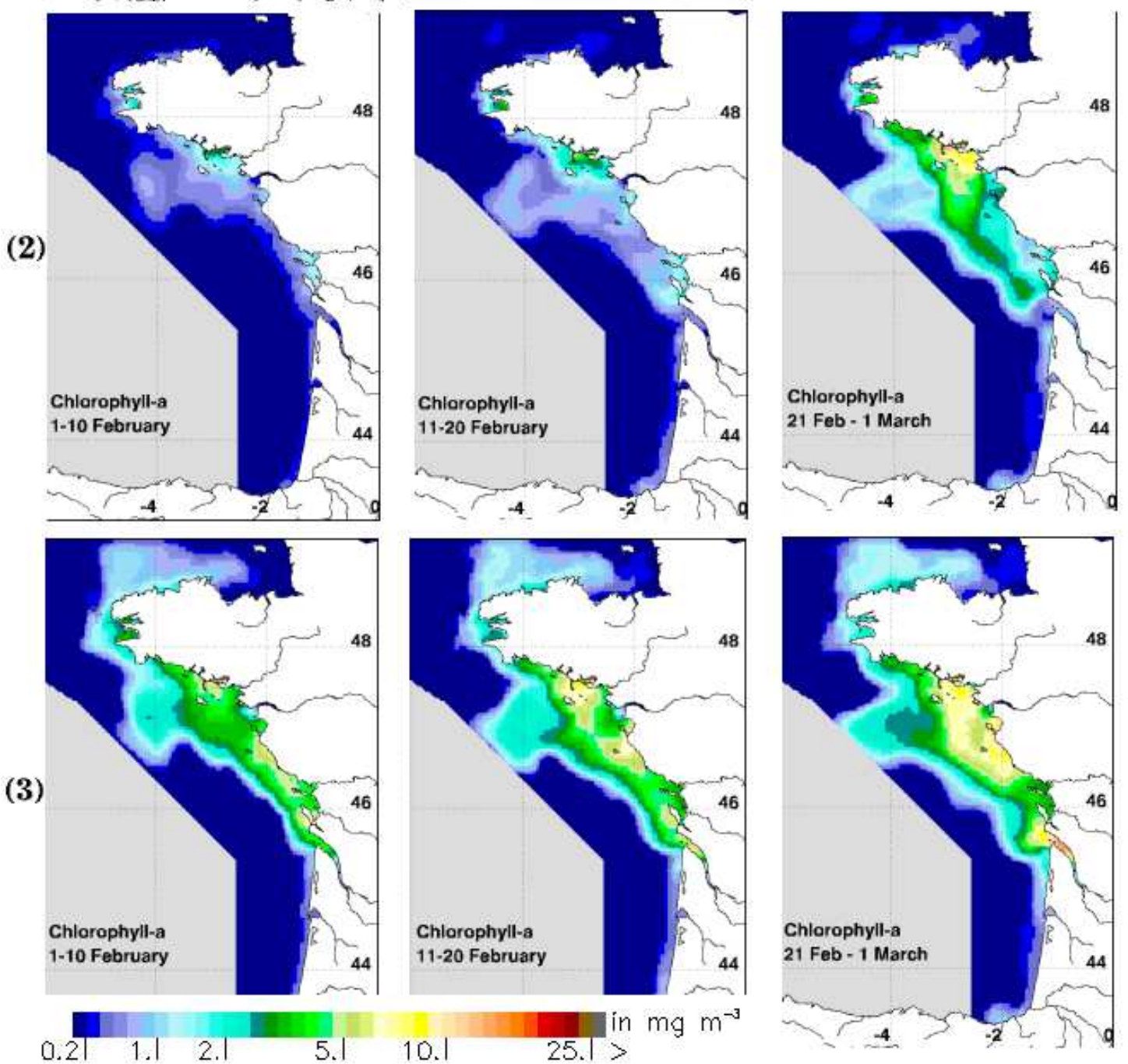

Fig. 9. Ten days mean situations calculated from SeaWiFS images (1), outputs of the nominal model (2), and outputs of the model without SPM-derived light attenuation, for beginning (a), mid (b) and late (c) February 2001. 


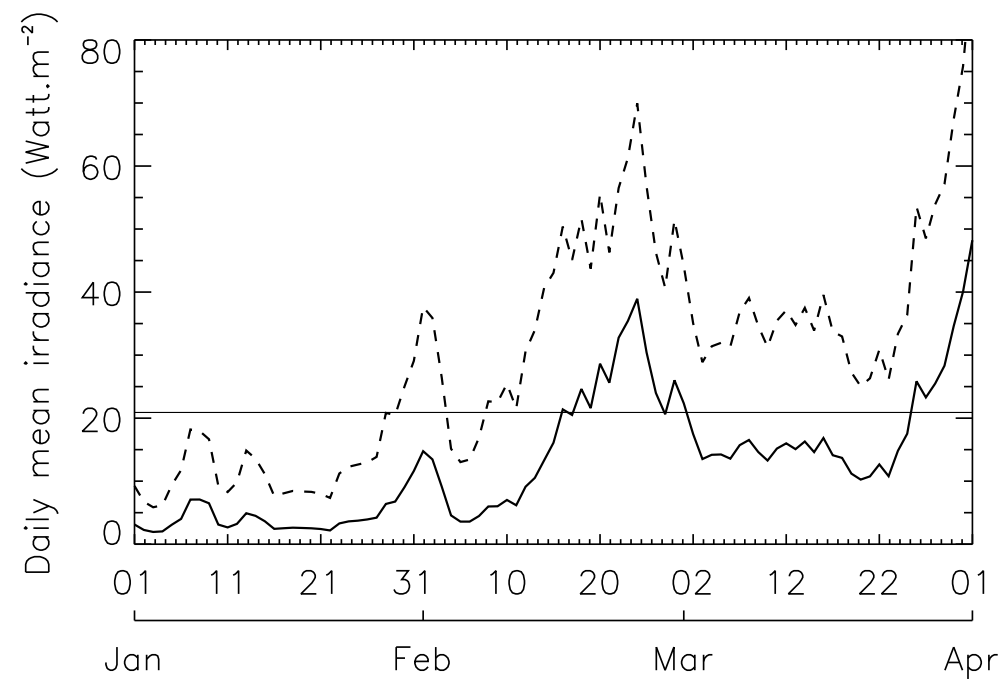

Fig. 10. Daily mean irradiance in the surface mixel-layer $\left(E_{m}\right)$ calculated from Riley's equation and derived from METEOSAT surface irradiance data. Continuous/dashed line is the model case with SPM considered/not considered in $K_{P A R}$

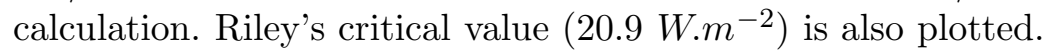

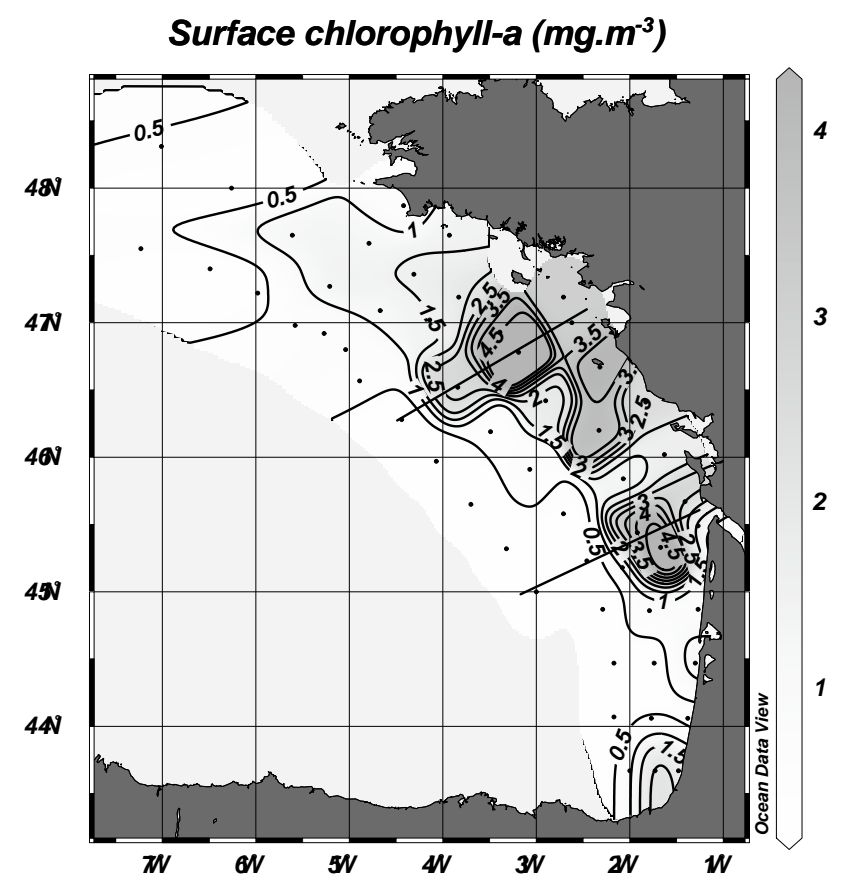

Fig. 11. Surface chlorophyll $a$ from the PEL01 cruise (30 April to 4 June 2001). Transects are for sections of Fig.14. 

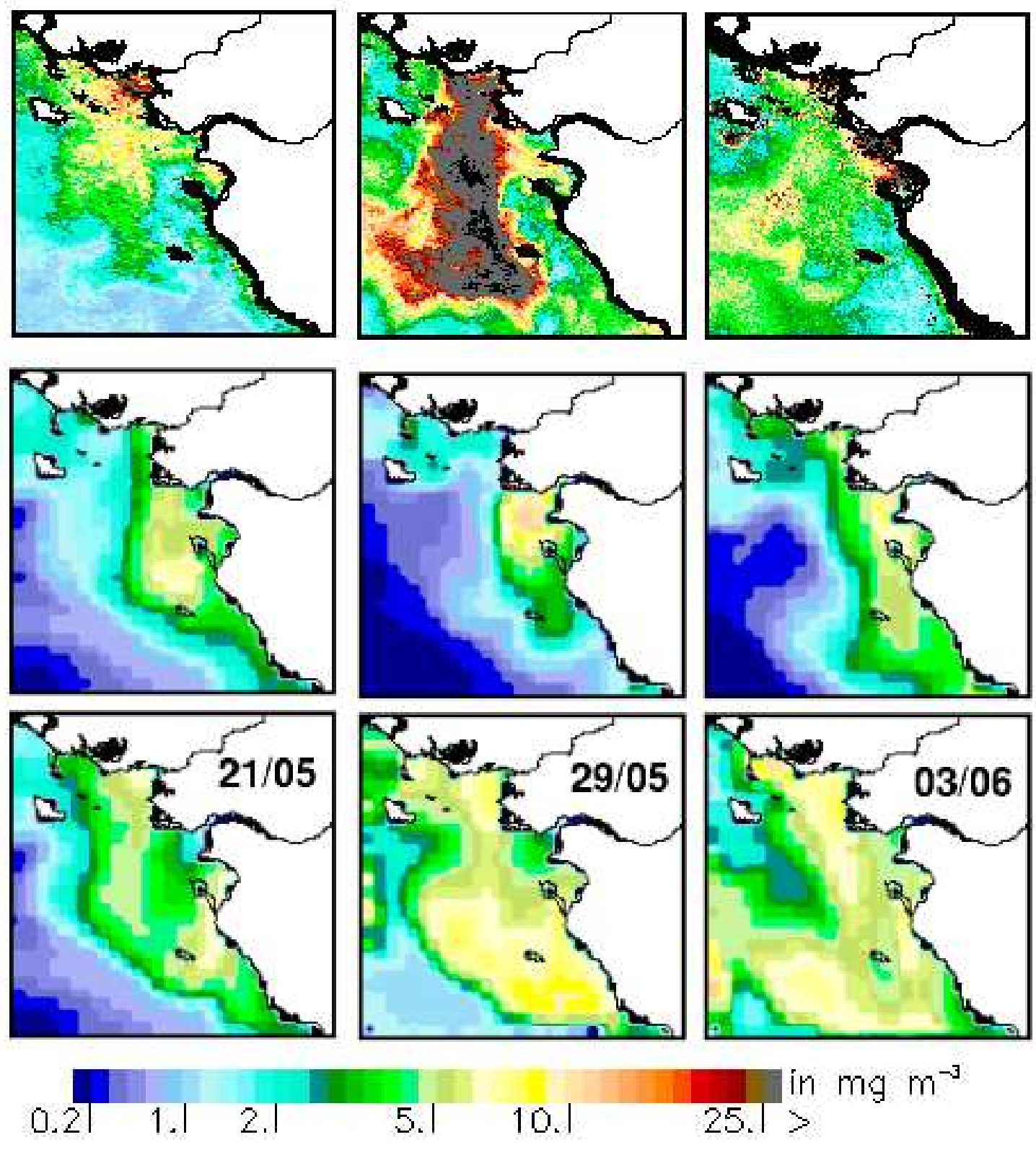

Fig. 12. Surface chlorophyll $a$ in the Loire plume from SeaWiFS (top), the model before (middle) and after (bottom) parameter optimization. 

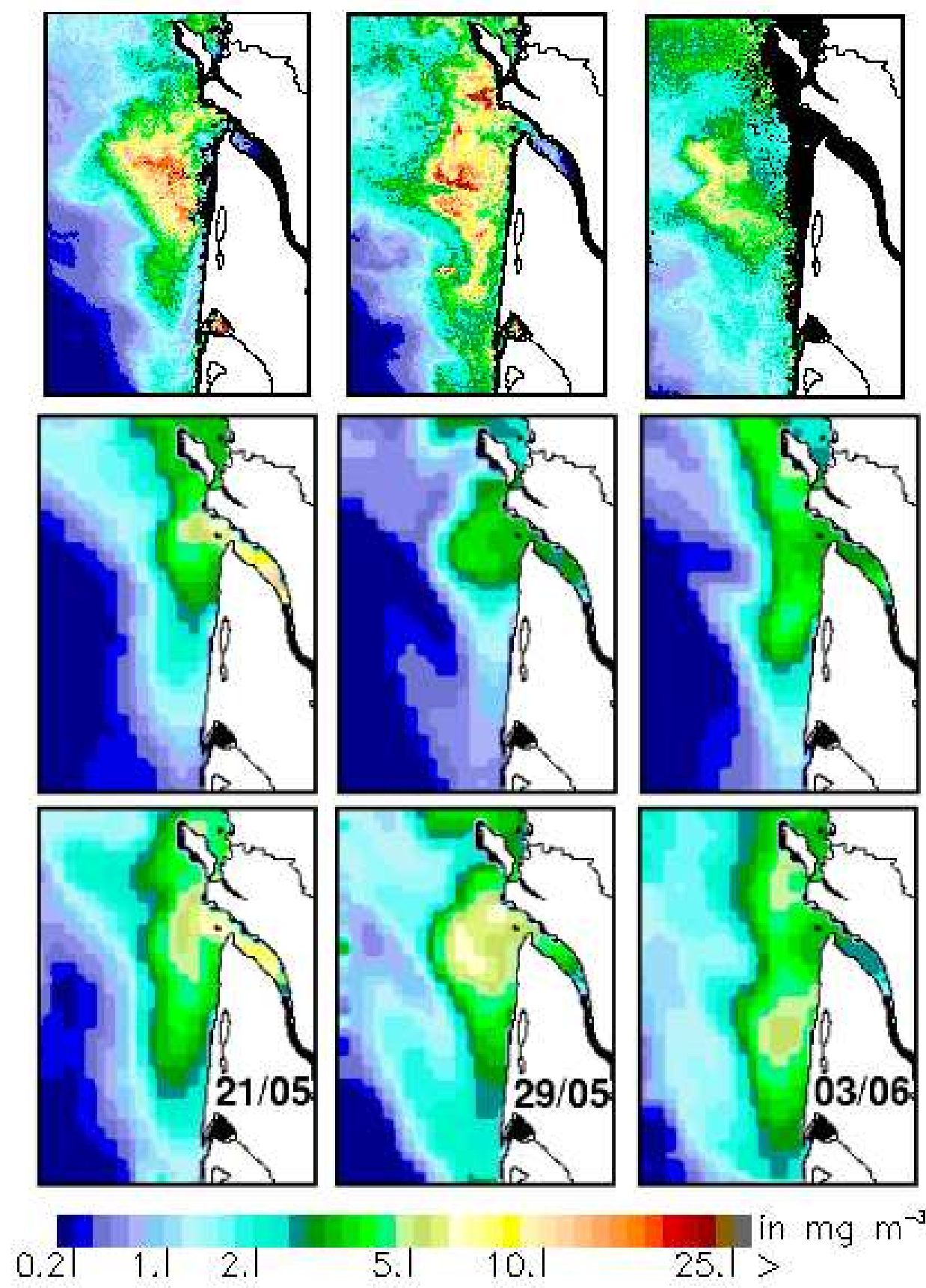

10.1

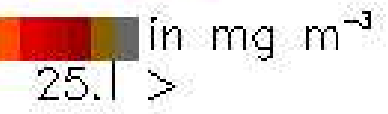

Fig. 13. Surface chlorophyll $a$ in the Gironde plume from SeaWiFS (top), the model before (middle) and after (bottom) parameter optimization. 

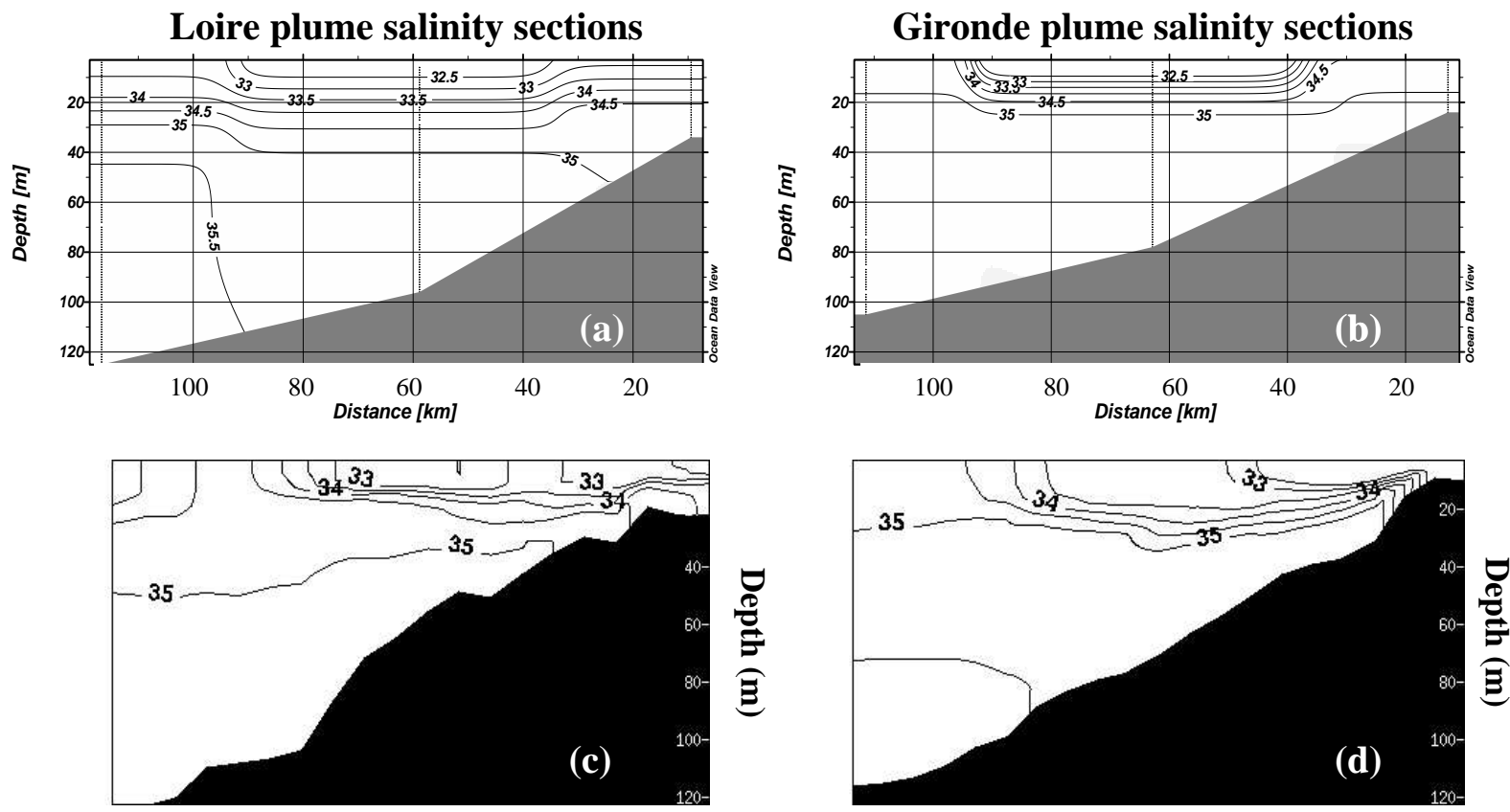

Fig. 14. Salinity sections of the transects of Fig.11 from PEL01 cruise (a,b) and from the model $(\mathrm{c}, \mathrm{d})$. a,c and b,d are sections of the Loire and Gironde plume, respectively. 

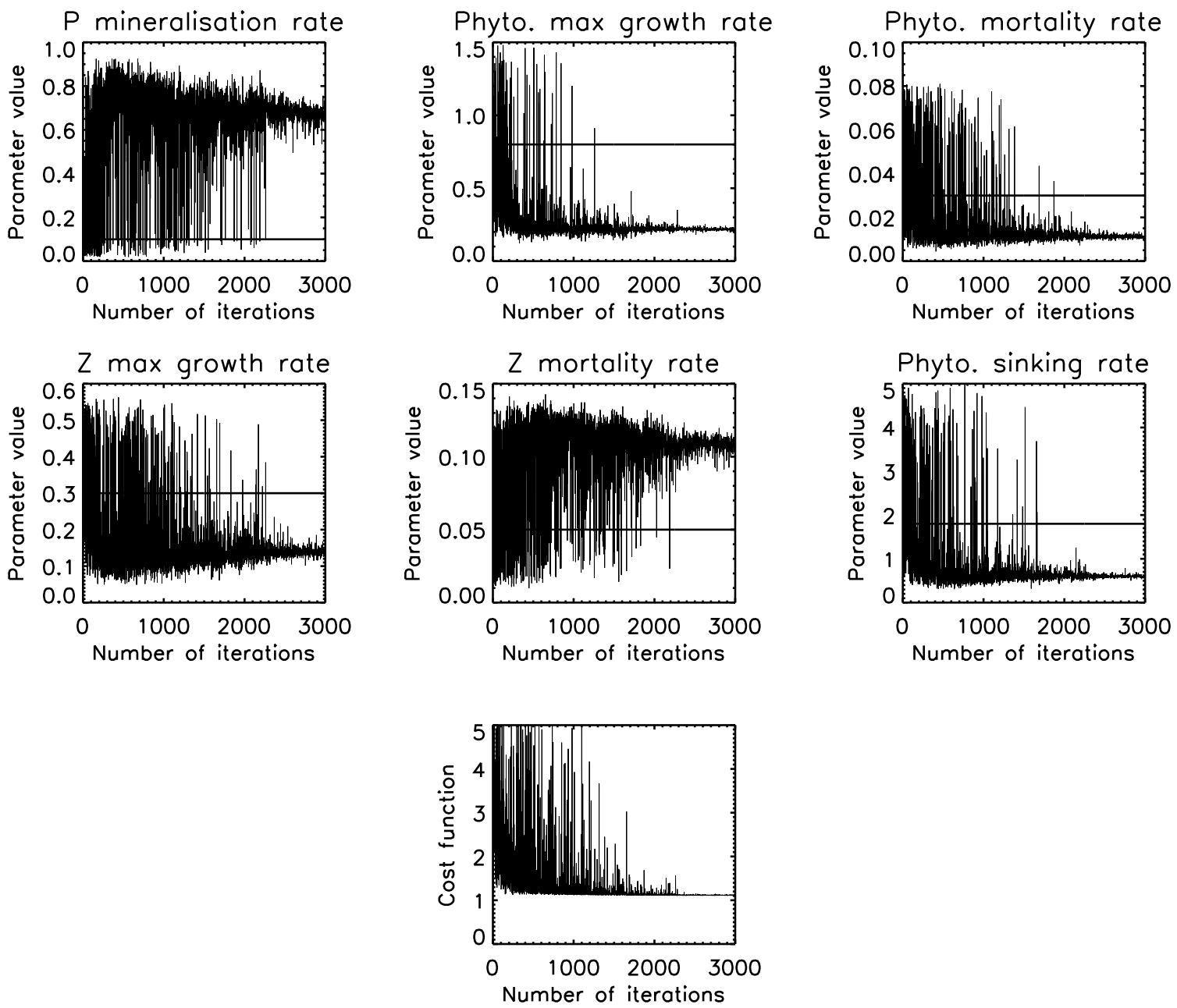

Fig. 15. Evolution of parameter and cost function values along the optimization iterations for the Loire real SeaWiFS data experiment. Continuous lines indicate the first-guess value for each parameter. 


\begin{tabular}{|c|c|c|c|c|}
\hline symbol & parameter & value & unit & source \\
\hline \multicolumn{5}{|c|}{ Phytoplankton } \\
\hline$r_{S i: N}^{P h y}$ & Silicon/Nitrogen ratio & 0.75 & mol.mol ${ }^{-1}$ & NUT01 \\
\hline$r_{P: N}^{P h y}$ & Nitrogen/Phosphorus ratio & 16 & mol.mol ${ }^{-1}$ & $\mathrm{R} 63$ \\
\hline$r_{C: N}^{P h y}$ & Carbon/Nitrogen ratio & 6.625 & mol.mol ${ }^{-1}$ & $\mathrm{R} 63$ \\
\hline \multicolumn{5}{|l|}{ Diatoms } \\
\hline$\mu_{\text {Diat }}^{0}$ & Specific growth rate & 0.8 & $d a y^{-1}$ & adjusted \\
\hline$m_{\text {Diat }}^{0}$ & Specific mortality rate & 0.03 & $d a y^{-1}$ & $\mathrm{C} 04$ \\
\hline$K_{\mathrm{NO}_{3}}^{\mathrm{Diat}}$ & Nitrate half-saturation & 2 & $\mu m o l . l^{-1}$ & L01 \\
\hline $\mathrm{K}_{\mathrm{NH}_{4}}^{\mathrm{Diat}}$ & Ammonium half-saturation & 1.5 & $\mu m o l . l^{-1}$ & L01 \\
\hline$K_{S i}^{D i a t}$ & Silicate half-saturation & 1 & $\mu m o l . l^{-1}$ & L01 \\
\hline$K_{P}^{\text {Diat }}$ & Phosphate half-saturation & 0.08 & $\mu m o l . l^{-1}$ & L01 \\
\hline$I_{o p t}^{\text {Diat }}$ & Optimum light irradiance & 50 & $W \cdot m^{-2}$ & adjusted \\
\hline \multicolumn{5}{|c|}{ Dinoflagellates } \\
\hline$\mu_{\text {Dino }}^{0}$ & Specific growth rate & 0.35 & $d a y^{-1}$ & $\mathrm{C} 04$ \\
\hline$m_{\text {Dino }}^{0}$ & Specific mortality rate & 0.02 & $d a y^{-1}$ & $\mathrm{C} 04$ \\
\hline$K_{\mathrm{NO}_{3}}^{\mathrm{Dino}}$ & Nitrate half saturation & 4 & $\mu m o l . l^{-1}$ & L01 \\
\hline$K_{\mathrm{NH}_{4}}^{\mathrm{Dino}}$ & Ammonium half-saturation & 0.9 & $\mu m o l . l^{-1}$ & L01 \\
\hline$K_{P}^{\text {Dino }}$ & Phosphate half-saturation & 0.06 & $W \cdot m^{-2}$ & L01 \\
\hline$I_{o p t}^{\text {Dino }}$ & Optimum light irradiance & 170 & $W \cdot m^{-2}$ & $\mathrm{C} 04$ \\
\hline \multicolumn{5}{|c|}{ Zooplankton } \\
\hline$\mu_{Z o o}^{0}$ & Specific growth rate & 0.3 & $d a y^{-1}$ & $\mathrm{C} 04$ \\
\hline$m_{Z o o}^{0}$ & Specific mortality rate & 0.05 & $d a y^{-1}$ & adjusted \\
\hline$m_{Z o o / B i o m}$ & Biomass-dependent mortality & 0.0006 & $d a y^{-1} \cdot\left(l \cdot \mu g^{-1}\right)$ & $\mathrm{C} 04$ \\
\hline$\epsilon^{0}$ & Specific excretion rate & 0.01 & $d a y^{-1}$ & $\mathrm{C} 04$ \\
\hline$\gamma$ & Ivlev coefficient & 0.25 & l. $\mu m o l$ & adjusted \\
\hline$P_{0}$ & Predation escape rate & 0.75 & $\mu g C h l a . l^{-1}$ & adjusted \\
\hline$\tau_{\text {assimil }}$ & Assimilation rate & 0.6 & s.u. & $\mathrm{C} 04$ \\
\hline$p_{\text {Diat }}$ & Preferency coef. for Diatoms & 1 & s.u. & L01 \\
\hline$p_{\text {Dino }}$ & Pref. coef. for Dinoflagellates & 0.1 & s.u. & L01 \\
\hline$r_{C: N}^{Z o o}$ & Carbon/Nitrogen ratio & 5.45 & s.u. & $\mathrm{P} 01$ \\
\hline \multicolumn{5}{|l|}{ Table 1} \\
\hline
\end{tabular}




\begin{tabular}{llccl}
\hline symbol & parameter & value & unit & source \\
\hline$W_{\text {min }}$ & Minimum sinking rate for Diatoms & 0.5 & m.day $^{-1}$ & L01 \\
$W_{\text {max }}$ & Maximum sinking rate for Diatoms & 1.8 & m.day $^{-1}$ & L01 \\
$w$ & Exponent for sinking rate of Diatoms & 0.2 & $s . u$. & L01 \\
$W_{\text {Det }}^{\text {phy }}$ & Sinking rate of phytoplankton detritus & 4 & m.day & L01 \\
$W_{\text {Det }}^{z o o}$ & Sinking rate of zooplankton detritus & 120 & m.day & adjusted \\
$W_{\text {spm }}$ & Sinking rate of SPM & 1 & m.day & adjusted \\
\hline
\end{tabular}

Table 2

List of sinking rate parameters. L01 : Loyer (2001).

\begin{tabular}{|c|c|c|c|c|}
\hline symbol & parameter & value & unit & source \\
\hline \multicolumn{5}{|c|}{ Mineralisation (water) } \\
\hline $\operatorname{rmin}_{\mathrm{Neau}}^{0}$ & Specific mineralisation rate for $\mathrm{N}$ & 0.02 & $d a y^{-1}$ & adjusted \\
\hline$r d i s_{\text {Sieau }}^{0}$ & Specific mineralisation rate for $\mathrm{Si}$ & 0.005 & $d a y^{-1}$ & adjusted \\
\hline $\operatorname{rmin}_{P e a u}^{0}$ & Specific mineralisation rate for $\mathrm{P}$ & 0.1 & $d a y^{-1}$ & $\mathrm{C} 04$ \\
\hline$r n i t_{e a u}^{0}$ & Specific nitrification rate & 0.02 & $d a y^{-1}$ & adjusted \\
\hline \multicolumn{5}{|c|}{ Mineralisation (sed.) } \\
\hline $\operatorname{rmin}_{N \text { sed }}^{0}$ & Specific mineralisation rate for $\mathrm{N}$ & 0.002 & $d a y^{-1}$ & adjusted \\
\hline rdis ${ }_{\text {Sised }}^{0}$ & Specific mineralisation rate for $\mathrm{Si}$ & 0.005 & $d a y^{-1}$ & adjusted \\
\hline $\operatorname{rmin}_{P s e d}^{0}$ & Specific mineralisation rate for $\mathrm{P}$ & 0.015 & $d a y^{-1}$ & adjusted \\
\hline$r n i t_{\text {sed }}^{0}$ & Specific nitrification rate & 0.02 & $d a y^{-1}$ & adjusted \\
\hline \multicolumn{5}{|c|}{ Phosphate adsorption } \\
\hline$C_{a d s}$ & $\mathrm{P}$ adsorption coefficient on SPM & 0.12 & l. $\mu m o l P^{-1} \cdot d a y^{-1}$ & $\mathrm{C} 04$ \\
\hline$C_{d e s}$ & $\mathrm{P}$ desorption coefficient & 2.4 & $d a y^{-1}$ & $\mathrm{C} 04$ \\
\hline$k_{a d s}^{\max }$ & Max. capacity of SPM adsorption & 40 & $\mu m o l P . g^{-1}$ & $\mathrm{C} 04$ \\
\hline
\end{tabular}

Table 3

List of parameters for particulate matter. C04 : Cugier et al. (2004). 


\begin{tabular}{|c|c|c|c|c|c|c|c|c|}
\hline \multirow[b]{2}{*}{ Coefficient } & \multicolumn{4}{|c|}{ Loire } & \multicolumn{4}{|c|}{ Gironde } \\
\hline & $S_{C h l}$ & $S_{Z o o}$ & $S_{P_{4}}$ & $S_{P_{d e t}}$ & $S_{C h l}$ & $S_{Z o o}$ & $S_{P_{4}}$ & $S_{P_{d e t}}$ \\
\hline Max sinking rate for Diatoms $\left(W_{\max }\right)$ & -0.22 & -0.08 & 0.07 & -0.21 & -0.38 & -0.07 & 0.07 & -0.67 \\
\hline Min sinking rate for Diatoms $\left(W_{\min }\right)$ & -0.12 & -0.07 & 0.06 & -0.12 & -0.13 & -0.06 & 0.04 & -0.16 \\
\hline Exp. for sinking rate of Diatoms $(w)$ & -0.11 & -0.04 & 0.04 & -0.11 & -0.17 & -0.04 & 0.03 & -0.25 \\
\hline Zoo specific growth rate $\left(\mu_{Z o o}^{0}\right)$ & -0.52 & 0.31 & 0.63 & -0.35 & -0.31 & 0.35 & 0.32 & -0.54 \\
\hline Ivlev coefficient $(\gamma)$ & -0.33 & 0.24 & 0.44 & -0.25 & -0.22 & 0.28 & 0.23 & -0.41 \\
\hline Assimilation rate $\left(\tau_{\text {assimil }}\right)$ & -0.35 & 0.63 & 0.52 & -0.25 & -0.20 & 0.54 & 0.28 & -0.43 \\
\hline Zoo specific mortality rate $\left(m_{Z o o}^{0}\right)$ & 0.19 & -0.86 & -0.42 & 0.18 & 0.11 & -0.86 & -0.18 & 0.38 \\
\hline Biomass-dependent mort. $\left(m_{Z o o / B i o m}\right)$ & 0.04 & -0.09 & -0.08 & 0.03 & 0.01 & -0.01 & -0.02 & 0.01 \\
\hline Sinking rate of phyto detritus $\left(W_{D e t}^{p h y}\right)$ & -0.01 & 0.0 & -0.02 & -0.16 & -0.01 & -0.02 & -0.06 & -0.27 \\
\hline Sinking rate of zoo detritus $\left(W_{D e t}^{z o o}\right)$ & -0.02 & -0.02 & -0.05 & -0.96 & -0.04 & -0.02 & -0.13 & -0.91 \\
\hline $\mathrm{P}$ desorption coefficient $\left(C_{d e s}\right)$ & 0.08 & 0.13 & 0.16 & 0.09 & 0.04 & 0.07 & 0.07 & 0.04 \\
\hline Maximum SPM adsorption $\left(k_{a d s}^{\max }\right)$ & -0.08 & -0.14 & -0.17 & -1.0 & -0.04 & -0.07 & -0.07 & -0.04 \\
\hline Dissolved $\mathrm{P}$ river load & 0.02 & 0.05 & 0.05 & 0.04 & 0.01 & 0.02 & 0.03 & 0.02 \\
\hline Particulate $\mathrm{P}$ river load & 0.02 & 0.03 & 0.04 & 0.04 & 0.0 & 0.0 & 0.0 & 0.01 \\
\hline Diatoms specific growth rate $\left(\mu_{\text {Diat }}^{0}\right)$ & -0.13 & 0.06 & -1.78 & -0.09 & -0.12 & 0.06 & -1.38 & -0.16 \\
\hline Phyto specific mortality rate $\left(m_{D i a t}^{0}\right)$ & -0.21 & -0.23 & 0.26 & 0.61 & -0.32 & -0.20 & 0.45 & 0.65 \\
\hline Phosphate half-saturation $\left(K_{S i}^{\text {Diat }}\right)$ & -0.03 & -0.06 & 0.61 & -0.04 & -0.03 & -0.05 & 0.70 & -0.04 \\
\hline Optimum light irradiance $\left(I_{o p t}^{\text {Diat }}\right)$ & 0.06 & -0.03 & 0.13 & 0.06 & 0.05 & -0.01 & 0.13 & 0.07 \\
\hline Specific excretion rate $\left(\epsilon^{0}\right)$ & 0.07 & -0.12 & 0.03 & 0.08 & 0.05 & -0.14 & 0.07 & 0.16 \\
\hline Predation escape rate $\left(P_{0}\right)$ & 0.15 & -0.18 & -0.21 & 0.17 & 0.11 & -0.22 & -0.07 & 0.30 \\
\hline Specific P mineral. rate $\left(r m i n_{P e a u}^{0}\right)$ & 0.04 & 0.03 & 0.10 & -0.06 & 0.07 & 0.04 & 0.19 & -0.07 \\
\hline
\end{tabular}
Table 4

Sensitivity values for a variation of $+25 \%$ on the model parameters. Only parameters with a sensitivity $S_{C}>0.005$ are given. 


\begin{tabular}{ccccc|c}
\hline & Reference value & Min bound & Max bound & \multicolumn{2}{c}{ Estimated value } \\
Parameter & $P^{*}$ & $P_{0}$ & $P_{1}$ & Loire & Gironde \\
\hline$\left(\right.$ rmin $\left._{\text {Peau }}^{0}\right)$ & 0.1 & 0 & 0.5 & $0.060(40 \%)$ & $0.053(47 \%)$ \\
$\left(\mu_{\text {Diat }}^{0}\right)$ & 0.8 & 0 & 4.0 & $0.76(5.5 \%)$ & $0.78(2.5 \%)$ \\
$\left(m_{\text {Diat }}^{0}\right)$ & 0.03 & 0 & 0.15 & $0.0280(6.5 \%)$ & $0.0279(7.0 \%)$ \\
$\left(\mu_{\text {Zoo }}^{0}\right)$ & 0.3 & 0 & 1.5 & $0.25(15 \%)$ & $0.27(7.5 \%)$ \\
$\left(m_{\text {Zoo }}^{0}\right)$ & 0.05 & 0 & 0.25 & $0.033(34 \%)$ & $0.041(18.3 \%)$ \\
$\left(W_{\text {max }}\right)$ & 1.8 & 0 & 9.0 & $1.70(5.8 \%)$ & $1.73(3.9 \%)$ \\
Cost function $(\mathrm{J})$ & & & & $0.0012(3.5 \%)$ & $0.0010(3.2 \%)$ \\
\hline
\end{tabular}

Table 5

Parameter values for the twin experiments. For the estimated value, the relative error is indicated between parenthesis.

\begin{tabular}{ccccc|c}
\hline & Reference value & Min bound & Max bound & \multicolumn{2}{c}{ Estimated value } \\
Parameter & $P^{*}$ & $P_{0}$ & $P_{1}$ & Loire & Gironde \\
\hline$\left(\right.$ rmin $\left._{\text {Peau }}^{0}\right)$ & 0.1 & 0.01 & 1.0 & 0.68 & 0.65 \\
$\left(\mu_{\text {Diat }}^{0}\right)$ & 0.8 & 0.08 & 1.6 & 0.22 & 0.55 \\
$\left(m_{\text {Diat }}^{0}\right)$ & 0.03 & 0.003 & 0.9 & 0.011 & 0.010 \\
$\left(\mu_{\text {Zoo }}^{0}\right)$ & 0.3 & 0.03 & 0.6 & 0.14 & 0.40 \\
$\left(m_{\text {Zoo }}^{0}\right)$ & 0.05 & 0.005 & 0.15 & 0.11 & 0.10 \\
$\left(W_{\text {max }}\right)$ & 1.8 & 0.18 & 5.4 & 0.59 & 0.56 \\
Cost function $(\mathrm{J})$ & $2.7(\mathrm{~L}) 1.76(\mathrm{G})$ & & & 1.11 & 0.78 \\
\hline
\end{tabular}

Table 6

Parameter values for the real data experiments on the Loire (L) and Gironde $(\mathrm{G})$ plumes. 